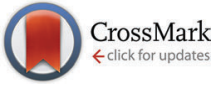

Cite this: J. Mater. Chem. C, 2016, 4, 6946

Received 8th May 2016,

Accepted 22nd June 2016

DOI: $10.1039 / \mathrm{c} 6 \mathrm{tc} 01881 \mathrm{e}$

www.rsc.org/MaterialsC

\section{n-Type doped transparent conducting binary oxides: an overview}

\begin{abstract}
Sebastian C. Dixon, ${ }^{a}$ David O. Scanlon, ${ }^{\text {bc }}$ Claire J. Carmalt ${ }^{a}$ and Ivan P. Parkin ${ }^{{ }^{a}}$
This article focuses on n-type doped transparent conducting binary oxides - namely, those with the general formula $M_{x} O_{y}: D$, where $M_{x} O_{y}$ is the host oxide material and $D$ is the dopant element. Such materials are of great industrial importance in modern materials chemistry. In particular, there is a focus on the search for alternatives to indium-based materials, prompted by indium's problematic supply risk as well as a number of functional factors. The important relationship between computational study and experimental observation is explored, and an extensive comparison is made between the electrical properties of a number of the most interesting experimentally-prepared materials. In writing this article, we aim to provide both an accessible tutorial of the physical descriptions of transparent conducting oxides, and an up-to-date overview of the field, with a brief history, some key accomplishments from the past few decades, the current state of the field as well as postulation on some likely future developments.
\end{abstract}

\section{Introduction}

\subsection{Transparent conducting oxides}

1.1.1 Background. Transparent conducting oxides (TCOs) are materials which have attracted much attention in recent decades on account of their unique and hugely useful properties. These materials might have once been considered unusual due to their exhibition of both transparency and conductivity, properties which according to the simplest description of band theory ought to be mutually exclusive. ${ }^{1,2}$ Band theory considers that when atoms combine to form a compound, their atomic electronic orbitals overlap to form molecular orbitals - the countless permutations of the bonding and antibonding combinations of atomic into molecular orbitals in a solid result in the blurring of discrete energy levels into a continuous 'band'. In a semiconductor, the energy level corresponding to the highest occupied molecular orbital (HOMO) in the ground state is referred to as the valence band maximum (VBM), while the lowest unoccupied molecular orbital (LUMO) is called the conduction band minimum (CBM). Traditionally, in order for electrical conduction to occur within the semiconductor material, ground state electrons must be excited from the VBM to the CBM, across an energy difference referred to as the band gap. This excitation requires energy input - one way this can occur is via the absorption of a photon. A wider band gap

\footnotetext{
${ }^{a}$ Materials Chemistry Research Centre, Department of Chemistry, University College London, 20 Gordon Street, London WC1H OAJ, UK. E-mail: i.p.parkin@ucl.ac.uk; Fax: +44 (o)20 7679 7463; Tel: +44 (0)20 76794669

${ }^{b}$ Kathleen Lonsdale Materials Chemistry, Department of Chemistry, University College London, 20 Gordon Street, London WC1H OAJ, UK

${ }^{c}$ Diamond House, Harwell Science and Innovation Campus,

Diamond Light Source Ltd., Didcot, Oxfordshire OX11 ODE, UK
}

requires a higher-energy photon in order for an electron to become excited into conduction. Therefore, according to this simplistic model, widening the band gap to greater than $E_{\mathrm{g}}=3.1 \mathrm{eV}$ in a material permits transparency to the visible portion of the spectrum, ${ }^{2}$ yet places greater separation between the VBM and $\mathrm{CBM}$ of the material, thereby decreasing the probability of exciting an electron into conduction.

TCOs have been developed to sidestep this conundrum by doping the material in order to facilitate the creation of charge carriers. In a more sophisticated description of the band model, there is an important distinction between the fundamental band gap such as that described above (i.e. the energy separation of the bulk HOMO and LUMO), and the optical band gap, which corresponds to the lowest-energy allowed optical transition. For a TCO to be useful, it is this optical band gap which becomes important for the transparency of the material, which means that in an n-type TCO, electrons can be injected from a nearby defect donor level directly into the conduction band in order to permit conductivity. In n-type TCOs, lattice defects in a metal oxide crystal, such as oxygen vacancies, proton interstitials and certain substitutional defects, effectively create an excess of electrons close to the defect site. If there is sufficient orbital overlap, it permits delocalisation of electrons from the defect sites such that electronic states at the CBM become filled, i.e. the Fermi level shifts above the CBM (see Fig. 1). This leads to an effect known as the Moss-Burstein shift, which effectively widens the optical band gap from simply: ${ }^{3}$

$$
E_{\mathrm{g}}=E_{\mathrm{CBM}}-E_{\mathrm{VBM}}
$$

to

$$
E_{\mathrm{g}}^{\mathrm{opt}}=E_{\mathrm{g}}^{\mathrm{MB}}+E_{\mathrm{g}}=E_{\mathrm{F}}-E_{\mathrm{VBM}}
$$




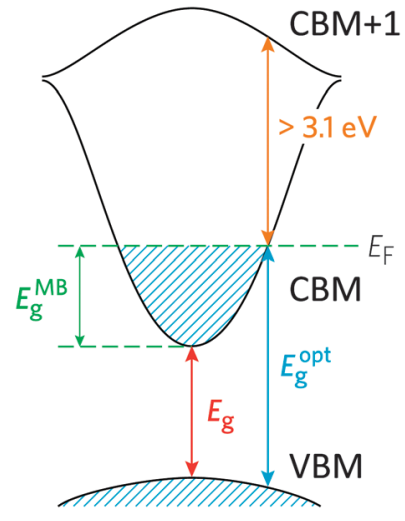

Fig. 1 Diagram of the optical widening effect of the Moss-Burstein shift.

since the Moss-Burstein shift is:

$$
E_{\mathrm{g}}^{\mathrm{MB}}=E_{\mathrm{F}}-E_{\mathrm{CBM}}
$$

where $E_{\mathrm{g}}$ is the fundamental energy gap separating the VBM and CBM, $E_{\mathrm{g}}^{\text {opt }}$ is the optical band gap corresponding to the smallest allowed optical transition from the VB to the $\mathrm{CB}$, $E_{\mathrm{g}}^{\mathrm{MB}}$ is the Moss-Burstein shift and $E_{\mathrm{F}}$ is the Fermi level. In this way, lattice defects in TCOs are able to simultaneously promote both electrical conductivity and optical transparency.

The band structure is a key aspect in designing a TCO; the optical band gap is just one such consideration. Other factors include the separation of the CBM of the host material from the vacuum level, i.e. the CBM depth or electron affinity $\left(E_{\mathrm{A}}\right)$, which affects the 'dopability' of the TCO. A higher value of $E_{\mathrm{A}}$ indicates greater ease of introducing charge carriers, i.e. a greater dopability. ${ }^{4,5} \mathrm{~A}$ large separation $\left(E_{\mathrm{g}}>3.1 \mathrm{eV}\right)$ between the Fermi level in the $\mathrm{CB}$ and the next electronic energy level (' $\mathrm{CBM}+1$ ' here) helps to prevent excitation of electrons to higher states within the conduction band, which might otherwise produce unwanted optical absorption. ${ }^{6}$ This effect is often referred to as free carrier absorption (FCA). These factors are clearly visible in Fig. 2, in which the doping by $\mathrm{Sn}$ of $\operatorname{In}_{2} \mathrm{O}_{3}$ raises the Fermi level above the CBM (i.e. the conduction band becomes partially filled), while the separation of the CBM from the CBM + 1 level
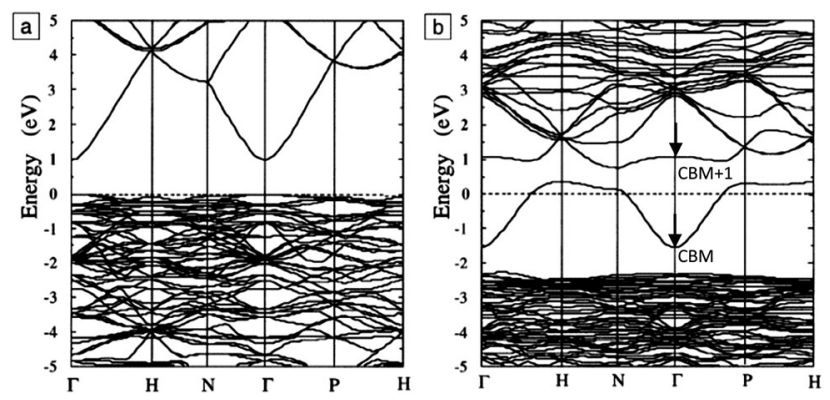

Fig. 2 Band structures of (a) undoped and (b) Sn-doped $\ln _{2} \mathrm{O}_{3}$. The Fermi level is set at $E=0 \mathrm{eV}$. The Brillouin zone centre is denoted by $\Gamma$, while $H$, $N$ and $P$ denote points at the Brillouin surface along high symmetry $k$-vectors in the reciprocal crystal lattice. The energy lines represent allowed electronic states at given $k$-points. Adapted with permission from Freeman et al. ${ }^{6}$ Copyright 2011 Cambridge University Press. appears to be around $3 \mathrm{eV}$ after doping (noting also that the fundamental band gaps tend to be underestimated by the density functional theory).

The conductivity of a TCO is related to the number of charge carriers and their ability to move through its crystal lattice, i.e. their mobility. The mobility of electrons within an n-type TCO is inversely proportional to their effective mass. This is a quantity used to express the mass that the electrons appear to have when moving within a periodic solid, in which their mobility is affected by their response to local forces within the crystal, expressed relative to their true mass $\left(m_{\mathrm{e}}\right)$. The key factor here is the orbital overlap between the metal cation in a host lattice and the oxygen, since it has been shown computationally that the $\mathrm{CB}$ in TCOs has significant oxygen character. It has been observed that metal-oxide structures with predominant s-character of the cation at the CBM are correlated with the lowest electron effective masses, suggesting that the degree of cation-oxide orbital hybridisation is a key factor. ${ }^{7}$ It is therefore likely that for this reason, TCOs based on an e.g. $\mathrm{TiO}_{2}$ host structure (where the CBM has 3d-character) are generally observed to have higher effective masses than $\mathrm{SnO}_{2}$-hosted TCOs. ${ }^{8,9}$ The calculated CB with a lower effective mass is described as having higher dispersity, and appears visually as having higher curvature at the band edges. ${ }^{2,10}$ This relationship can be easily demonstrated; to a parabolic approximation, the energy $E(k)$ of the CB at wavevector $k$ close to the Brillouin zone centre can be expressed as:

$$
E(k)=E_{0}+\frac{\hbar^{2} k^{2}}{2 m^{*}}
$$

where $E_{0}$ is a constant representing the energy at the band centre and $m^{*}$ is the electron effective mass. Then, the curvature of the $\mathrm{CB}$ is:

$$
\frac{\mathrm{d}^{2} E(k)}{\mathrm{d} k^{2}}=\frac{\hbar^{2}}{m^{*}}
$$

Thus, a CB with a high curvature corresponds to a low electron effective mass, which in turn facilitates high electron mobility. By computational modelling of TCO band structures, it is possible to predict the electronic properties of prospective TCO formulations by calculation of the electron effective mass. The electron mobility, electron density and (therefore) conductivity of inorganic materials are linearly related by the Boltzmann formulation:

$$
\sigma=n e \mu
$$

where $\sigma$ is the electrical conductivity expressed in $\mathrm{S} \mathrm{cm}^{-1}, n$ is the density of free charge carriers (i.e. electrons in an n-type TCO), $e$ is the electronic charge and $\mu$ is the electron mobility. The electrical resistivity, expressed in $\Omega \mathrm{cm}$, is simply:

$$
\rho=\frac{1}{\sigma}
$$

In order for a TCO material to be suitable for most electrode applications, it is desirable to maximise the charge carrier mobility (typically $\mu=50-70 \mathrm{~cm}^{2} \mathrm{~V}^{-1} \mathrm{~s}^{-1}$ ), minimise the 


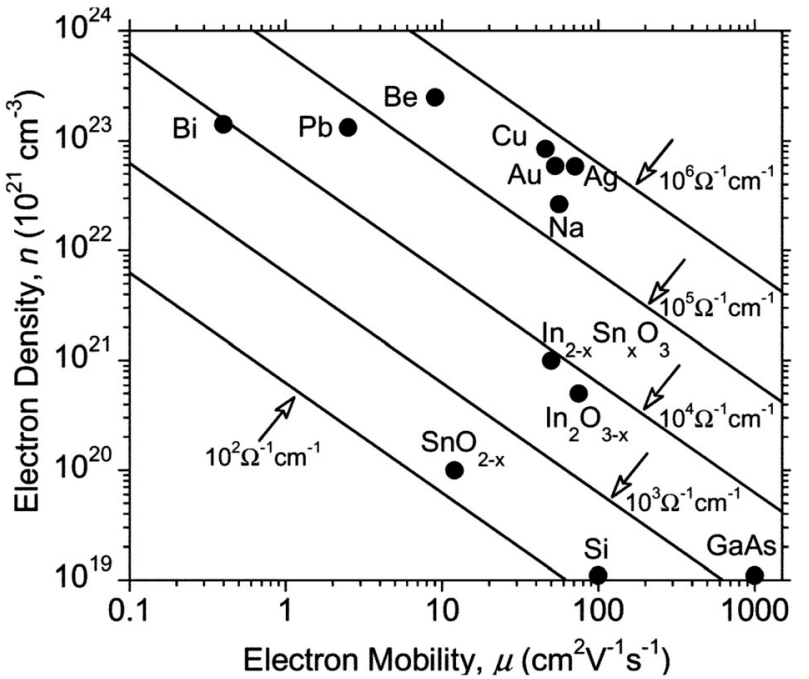

Fig. 3 Boltzmann relation of electron density, mobility and hence, conductivity. The latter is displayed as straight-line contours. Adapted with permission from Edwards et al. ${ }^{10}$ Copyright 2004 Royal Society of Chemistry.

electrical resistivity (ideally $\rho=10^{-4}-10^{-5}$ ) while keeping the carrier concentration below $2 \times 10^{21} \mathrm{~cm}^{-3}$ to minimise undesired optical absorption. It is clear from Fig. 3 that there are three somewhat distinct domains amongst inorganic materials regarding electrical properties: namely the semimetals (high carrier density, low electron mobility; top-left), highly conductive metals (both high carrier density and mobility; top-right) and semiconductors (low carrier density, high mobility; lower-right). While the introduction of a donor level close to the conduction band permits a wide optical band gap from the VBM to the CBM, the optical absorption associated with the promotion of electrons from the CBM to higher states places an upper limit on the carrier concentration in the CBM, such that the absorption coefficient $\alpha$ of the TCO is proportional to the density of free electrons $n$ by:

$$
\alpha=\sigma n
$$

where $\sigma$ is the absorption cross-section. Thick or highly doped TCO films therefore give rise to a pronounced optical absorption, which needs to be factored in when designing TCO components. ${ }^{11}$ Aside from this, increasing the dopant concentration of the TCO film also introduces an increasing density of defect (dopant) sites; in doing so, the increased conductivity conferred by the dopant's donor characteristics gradually becomes outweighed by an electron scattering effect from the increased number of defects. The mean free path length of charge carriers and therefore the free carrier relaxation time becomes reduced, which increases film resistivity. ${ }^{2,6,10,12}$ The effect of film thickness on transmission and resistivity is depicted in Fig. 4, and a similar relationship can be inferred for increasing the dopant concentration.

The demand for TCOs has soared in recent years due to them being key components in liquid crystal displays, touch-screen technology and photovoltaic cells, usually as electrodes. ${ }^{13}$ Other applications amongst a growing number include

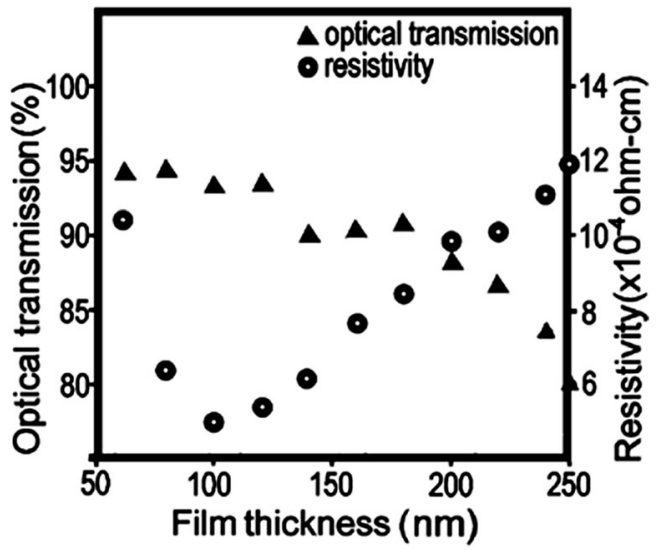

Fig. 4 Effect on optical transmission and resistivity of increasing thickness of ITO film on PET substrate. Adapted with permission from Wong et al. ${ }^{12}$ Copyright 2004 Elsevier.

antireflective coatings, ${ }^{14}$ waveguides in plasmonic devices, ${ }^{15}$ organic light-emitting devices ${ }^{12}$ and 'lab-on-a-chip' or bioanalytical devices. ${ }^{16}$ The current highest dollar-value market for TCOs is as transparent electrodes in flat-panel displays (FPDs), a market valued at US\$ $97 \mathrm{Bn}$ in 2014 and forecasted to reach US\$ 135 Bn by $2020 .{ }^{17}$ Meanwhile, low-emissivity ('low-e') TCO window coatings account for the greatest amount of TCO deposited annually. ${ }^{18}$ Current European and US legislation requires that all new buildings must feature solar control window coatings, which has assisted such products as fluorinedoped tin oxide (FTO) coatings on glass to contribute to a multibillion dollar market for low-e glass coatings. ${ }^{19}$ Ongoing social and technological development such as the increasing adoption of renewable energy sources and the continual growth of emerging economies therefore means that demand for TCOs is set to increase further and faster still. ${ }^{20}$

1.1.2 Historical perspective. TCOs were first reported in 1907 by German physicist Karl Baedeker, who sputter-coated cadmium onto a substrate followed by heat treatment in air to yield a cadmium oxide TCO. Incomplete oxidation of $\mathrm{Cd}$ in the heat treatment step led to a nonstoichiometric cadmium oxide, inevitably leaving oxygen vacancies within its crystal structure. The resulting pentavalent $\mathrm{Cd}^{2+}$ ions led to occupation of an electronic defect energy level close to the cadmium oxide conduction band minimum, facilitating easy promotion of electrons into that band. ${ }^{21}$ As the earliest recorded instance of a TCO, it was not optimal and did not exhibit resistivities anywhere near as low as pure metals, and would fully oxidise with time to yield the insulating wide band-gap semiconductor. Today, while Cd-based TCOs continue to be investigated such as CdO:In, which has resistivities an order of magnitude lower than the current market-leading TCOs, ${ }^{22}$ the extreme toxicity of Cd largely precludes its use on an industrial scale.

Later, in 1947, American inventor Harold McMaster patented a transparent conductive $\mathrm{SnO}_{2}$ coating which could be applied to glass via chemical vapour deposition (CVD) from stannous chloride, which became useful for planes when de-icing their windows at high altitude. ${ }^{23}$ Such TCO materials depend on 
oxygen vacancies and metal atom interstitials to lend conductivity, which are therefore not in practical use in modern TCOs due to the instability of such defects on longer timescales (i.e. gradual oxidation and interstitial migration). In 1954, Rupprecht discovered tin-doped indium oxide (ITO), a binary TCO material which to this day remains one of the most important and best-performing TCO materials on the market. ${ }^{24}$

In the decades that followed, countless transparent conducting oxide materials emerged from this fascinating field; in particular, while zinc oxide had long been known to be an intrinsic n-type semiconductor, its potential as a transparent conductor came to be recognised in research pioneered in the later 1970's to early 1980's by a fast-growing number of research groups, perhaps the most prolific of which being that of Minami et al. ${ }^{25}$ Work quickly moved on from intrinsically-doped $\mathrm{ZnO}$, in which conductivity is owed to defects such as oxygen vacancies and hydrogen or zinc interstitials, to extrinsically-doped materials such as indium-doped zinc oxide (IZO). ${ }^{26}$ It was not long before the field exploded with many more n-type doped binary oxide systems for transparent conducting applications. Many of the most notable developments of this now expansive field shall be explored herein.

1.1.3 Choosing a synthetic route. Any two given transparent conducting oxide films with the same chemical compositions can possess significantly different properties depending on their means of deposition. For instance, applications such as photovoltaic (PV) cells where the TCO layer meets a photon-absorbing layer at a heterojunction must have very low surface roughness, in order to make good contact. Deposition techniques such as DC magnetron sputtering would therefore be preferable in such an instance, where a smooth film is deposited on the substrate ${ }^{27}$ whereas we might expect that an inkjet-printed film, which deposits nanoparticles on the substrate and therefore has a high surface roughness (even after sintering), would make poorer contact at a heterojunction. However, inkjet printing is an inexpensive process, which minimises precursor wastage and offers a means of scalable high-throughput production of patterned TCO films for certain applications. ${ }^{28}$

The relatively small concentration of dopant in the host material (typically 1-5 at\%) is optimised by the trade-off between dopant carrier concentration versus increasing electron scattering effects at the dopant sites. This means that since free carrier densities in TCOs are low relative to metals, the mobility of the electrons within the TCO becomes the crucial factor in determining the conductivity of the material. ${ }^{29}$ It is also for this reason that TCO preparation methods which do not involve crystalline growth ultimately yield films with a high electrical resistance, i.e. that there is an abundance of physical boundaries which charge carriers must overcome and therefore their mobility is low. For example, indium-tin-oxide (ITO) thin films printed from a dispersion of $25 \mathrm{~nm}$ ITO nanoparticles, while achieving good optical transmittance at $84 \%$, were only able to reach a minimum resistivity of $1.5 \times 10^{-2} \Omega \mathrm{cm}^{28}$ Compare this with a typical polycrystalline ITO film grown by DC magnetron sputtering at $200{ }^{\circ} \mathrm{C}$, which has a transmittance over $92 \%$ in the visible region and a much lower resistivity

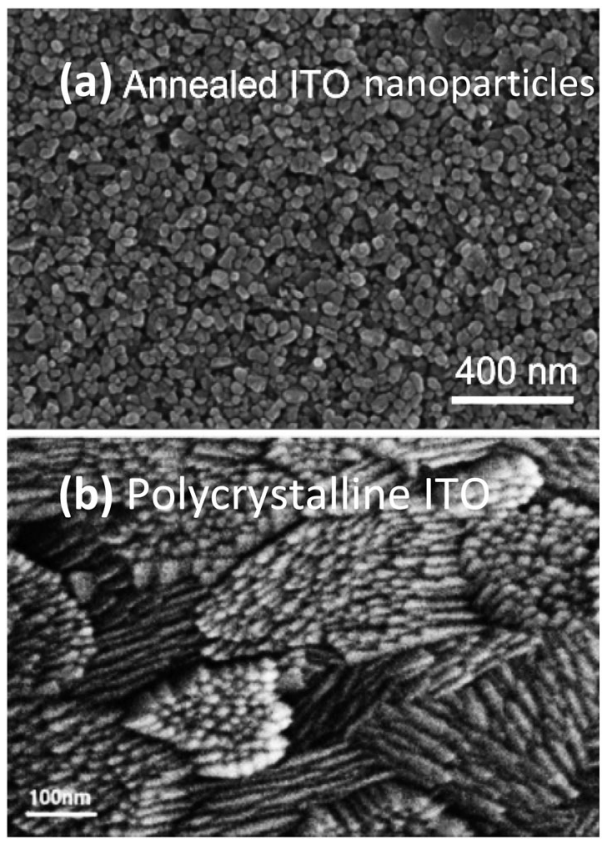

Fig. 5 Scanning electron micrographs from (a) an ITO thin film inkjetprinted from $25 \mathrm{~nm}$ nanoparticles and annealed at $450{ }^{\circ} \mathrm{C}_{1}^{28}$ and; (b) conventional DC magnetron sputtered polycrystalline ITO film deposited at $200{ }^{\circ} \mathrm{C} .{ }^{27}$ Adapted with permission from Jeong et al. and Betz et al. ${ }^{27,28}$ Copyright (a) 2010 and (b) 2006 Elsevier.

of $1.5 \times 10^{-4} \Omega \mathrm{cm} .{ }^{27}$ The reason for the discrepancy becomes more apparent in the scanning electron micrographs displayed in Fig. 5; it is evident that the polycrystalline film contains large (200-400 nm) well-oriented domains, while the inkjet-printed film of annealed nanoparticles contains a randomly-aligned physical boundary at the edge of each nanoparticle (i.e. every $25 \mathrm{~nm}$ ). Therefore, due to the resistance faced by charge carriers at these physical boundaries, it would be expected that their mobility, and consequently the conductivity of the material, would be hampered in the annealed inkjet-printed film. As such, in choosing a synthetic procedure for a TCO product it is important to weigh the benefits of the technique against its cost, simplicity and safety, and the desired properties of the TCO material.

It is possible to tune the physical properties of the TCO in order to suit the application. For the PV heterojunction, to facilitate efficient charge transfer from the photo-absorbing layer to the TCO, there must also be optimal overlap of the energy levels of both layers, as determined by the TCO work function this can be tuned by adjusting the relative concentration of components within a multi-component TCO. ${ }^{30}$ For instance, it was recently demonstrated by computation that the band gap of $\mathrm{SnO}_{2}$, which is sufficiently wide for visible transparency, can be controllably narrowed by alloying with isoelectronic $\mathrm{PbO}_{2}$, which has a narrow band gap but a large CBM to CBM + 1 gap and low electron effective mass. The properties of the alloying materials can combine to compliment one another, and in doing so, the CBM is lowered (i.e. the electron affinity is increased) to facilitate band alignment and Ohmic contact with other materials, 
while the Fermi level becomes positioned above the CBM to enable TCO functionality. The authors invite experimental verification. $^{2}$

\subsection{Indium-tin-oxide and the search for an alternative}

1.2.1 Indium: cost and supply risk. Currently, the most effective and utilised TCO material for electronic applications is tin-doped indium oxide (ITO), preferred on account of possessing both a high optical transmittance in the visible range, whilst also having a very low resistivity (typically $1-2 \times 10^{-4} \Omega \mathrm{cm}$ for polycrystalline ITO). ${ }^{18,30}$ However, issues arise with ITO on account of the unpredictable nature of the cost per unit mass of indium, due to its very low natural abundance and its subsequent production only as a by-product.

Limited global supply has led to competition over the control of the resource and therefore limited availability of indium. The EU in particular is entirely dependent on imports for its indium supply, meaning that TCO manufacture within the EU, as well other indium-dependent low-carbon technologies such as nuclear control rod manufacture, suffers severely from the indium supply risk (see Fig. 6). ${ }^{20}$

1.2.2 The demand for flexible TCOs. The interest in recent years for flexible transparent conductive materials (TCMs), driven by their ease of handling (lightweight, easier to transport, less prone to fracture) and low-cost manufacture (roll-to-roll continuous mass fabrication), has further spurred the search for alternatives to ITO. ${ }^{31}$ The high temperatures required to obtain polycrystalline ITO (generally $T>400{ }^{\circ} \mathrm{C}$ ) preclude its deposition on flexible substrates, which are generally polymers such as polyethylene terephthalate (PET) and cannot be processed above the glass transition temperature. While some progress has been made in low-temperature deposition of amorphous ITO films onto PET substrates using techniques such as radiofrequency (RF) magnetron sputtering ${ }^{12}$ and pulsed laser deposition, ${ }^{32}$ amorphous TCO films generally have inferior electronic properties to the polycrystalline films $\left(\rho=5-7 \times 10^{-4} \Omega \mathrm{cm} v s . \rho=\right.$ $1-2 \times 10^{-4} \Omega \mathrm{cm}$ for amorphous $v s$. polycrystalline ITO), though nitrogen-doped tin oxide may be an important exception to this trend. ${ }^{33}$ It has also been demonstrated recently that amorphous ITO films on flexible substrates will sustain a lesser degree of bending with fewer bending cycles before failure, as compared with polycrystalline films of the same material. ${ }^{34}$ Some work has gone into remedying this issue by fabrication of TCOmetal-TCO multilayer surface structures, which makes feasible the use of amorphous semiconductors deposited at low temperatures on flexible substrates by enhancing their electronic properties with a sandwiched thin metal layer such as Ag. The ductility of the metal layer enables continued operation of the device even when beyond the failure strain of the TCO. ${ }^{31}$ Crucially however, ITO is a brittle material with a critical strainto-failure of just $1.5 \%$ (for both bending and stretching tests) ${ }^{31}$ cracks develop irreversibly in ITO thin films from $36^{\circ}$ up to a maximum bending angle of $60^{\circ}$, which gradually reduces the conductivity across three orders of magnitude as the bend approaches its maximum. On the other hand, graphene for example is able to operate efficiently as a transparent conductor under bending angles of up to $138^{\circ}$, with minimal loss to its operational characteristics. ${ }^{35}$

1.2.3 Improving the conductivity. Further motivation for replacing ITO exists in order to find TCOs with improved resistivity characteristics - there is currently an upper limit to the size of flat-panel displays (FPDs) set by the TCO resistivity,

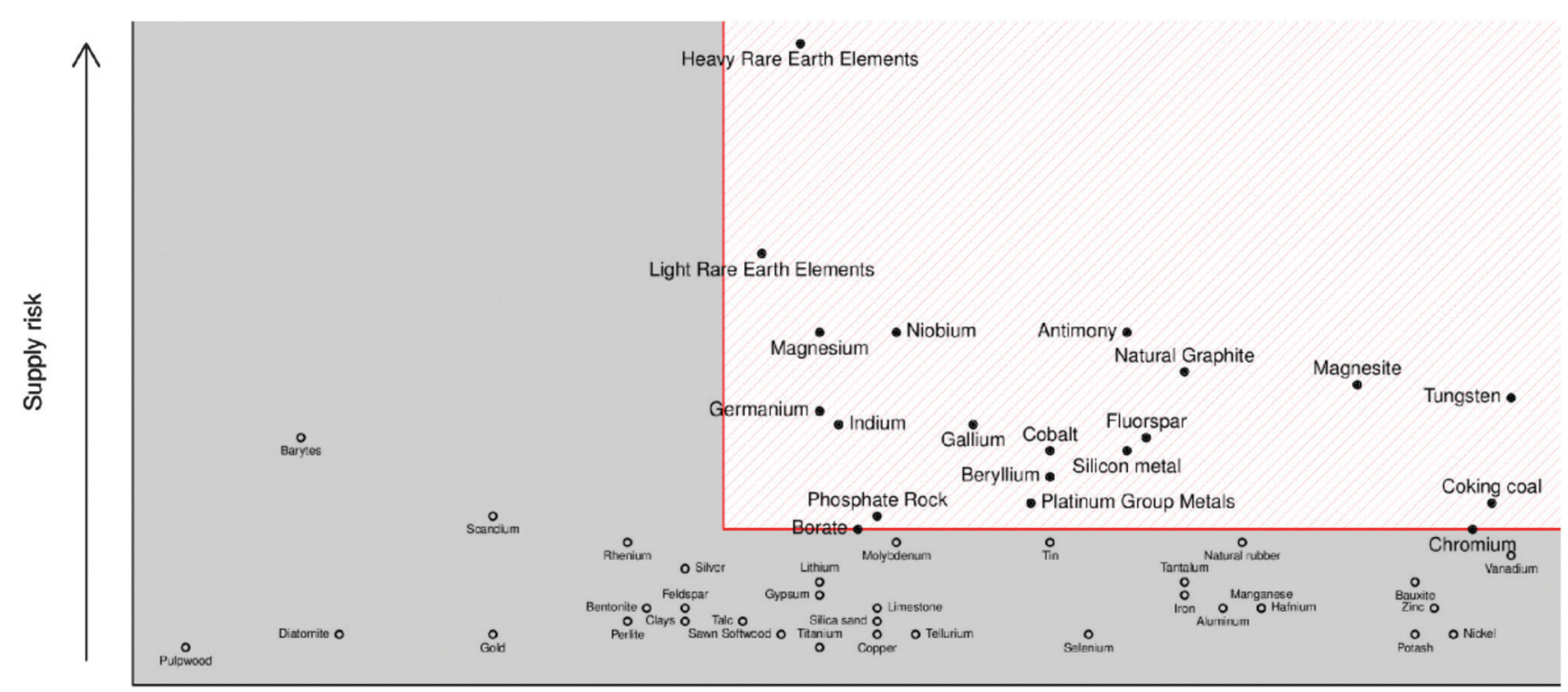

Economic importance

Fig. 6 European Commission report for raw material criticality (2013 data, revised \& published 2014). ${ }^{69}$ Adapted with permission from the European Commission. Copyright 2014 European Commission, DG Internal Market, Industry, Entrepreneurship and SMEs (DG GROW). 
due to the visible change in brightness across the display as it becomes larger. The demand for increasingly large FPDs for applications such as active signage and bigger televisions creates a need for improved TCO formulations. In particular, FPD technology such as the now-widely popular OLED is highly currentdependent and requires transparent electrodes with both much greater conductivity ${ }^{18}$ and higher work function (in order to improve band alignment with hole injection or extraction layers in OLED devices). ${ }^{31}$ It is also well known that the work function and chemical composition of ITO at its surface is highly dependent on the method of cleaning, indicating that ITO is unstable to oxidation - this becomes particularly apparent when fluorinedoped tin oxide (FTO) exhibits no such dependence, therefore further supporting that there is still room to improve on ITO. Likewise, FTO, as well as other alternative TCOs such as ZnO:Al and $\mathrm{ZnO}: \mathrm{Ga}$, does not suffer greatly from the thermal or chemical instability that affects the electrical properties of ITO. ${ }^{68}$

Therefore, investigation into alternatives to the highly successful ITO as a TCO material has become necessary, in order to find cheaper, more capable, more earth-abundant materials. The search for a viable alternative seeks to optimise a number of figures of merit such as optical transmission, haze, resistivity, charge carrier concentration and mobility, etchability, 'green' processability and affordability. This wide range of desirable properties has led to some TCOs becoming preferable over others depending on the context of application, for example etchability in transparent circuitry or band alignment of a new TCO with other existing materials within an established device, with no single TCO formula therefore being universally ideal. ${ }^{7}$

\section{2 n-Type doping of binary oxides}

\subsection{Background}

As it stands, the industry standard TCOs used are largely limited to the post-transition metal oxides $\mathrm{ZnO}, \mathrm{In}_{2} \mathrm{O}_{3}$ and $\mathrm{SnO}_{2}$, and subsequent mixtures of these such as tin- or zinc-doped indium oxide (ITO and IZO). ${ }^{18}$ The excellent metal-oxide orbital overlap in these structures gives rise to low electron effective masses (see Fig. 8) and therefore high electron mobilities. This, together with their deep CBMs (high dopability) and wide band gaps (see Fig. 7), ${ }^{2}$ is what makes these three important host structures for TCOs. Doped zinc oxide and tin oxide TCO materials have received particular attention in recent years on account of the indium supply risk, ${ }^{69}$ often with such dopants as to yield n-type TCOs (e.g. $\mathrm{SnO}_{2}: \mathrm{F}^{36,37} \mathrm{SnO}_{2}: \mathrm{Sb},{ }^{29,56-58} \mathrm{ZnO}: \mathrm{F}^{40,41} \mathrm{ZnO}: \mathrm{B},{ }^{44-46}$ $\mathrm{ZnO}: \mathrm{Ga},{ }^{48,49} \mathrm{ZnO}: \mathrm{Al},{ }^{47,70}$ etc.). In particular, the heavy focus on n-type doping of $\mathrm{SnO}_{2}$ is probably owing in part to doubts within the community as to whether efficient p-type doped $\mathrm{SnO}_{2}$ can ever be realised. ${ }^{4}$ Much research has gone into investigating a number of dopant elements; in n-type TCOs, these are usually substitutional dopant atoms which are selected in such a way that excess electrons become available at the dopant site. A comparison of a number of experimentally-prepared n-type doped TCOs is given in Table 1 , and can be referred to as a summary of the materials reviewed here. While the traditional

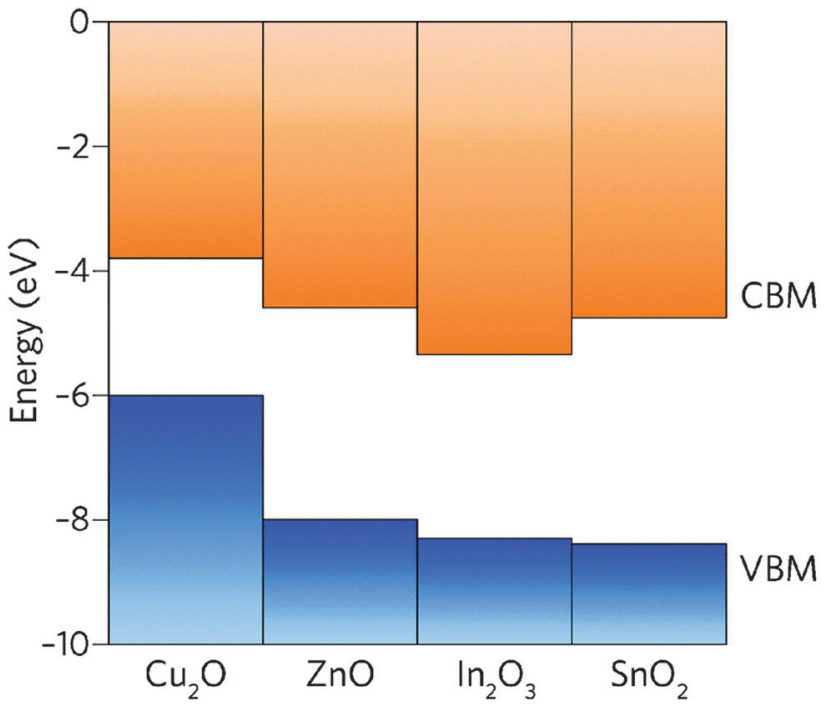

Fig. 7 Calculated band gaps of common TCO host structures. The vacuum level is set at $E=0 \mathrm{eV}$. Adapted from Ganose. ${ }^{2}$

'look-and-see' approach of doping aliovalent atoms into crystal sites (e.g. $\mathrm{Al}^{3+}$ on a $\mathrm{Zn}^{2+}$ site or $\mathrm{F}^{-}$on an $\mathrm{O}^{2-}$ site in $\mathrm{ZnO}$ ) has been reasonably effective in the past for screening TCO materials, the seemingly endless range of possible permutations of metal-oxide host structures and dopants has more recently been narrowed significantly with the aid of high-throughput computational analysis. $^{7}$

Computational simulations of hypothetical TCO materials have enabled screening of a wide range of possible materials and their properties, enabling us, with more power than ever before, to narrow the search of the many possible combinations of metal-oxide host and p-type or n-type dopants and their concentrations. It is possible to model the band structures, electron effective masses and mobilities in this way. Perhaps unfortunately, in one particular landmark high-throughput computational study, one of the most effective TCO materials amongst thousands of alternatives was found to remain the tindoped indium oxide (ITO), the present industry standard TCO, though there are of course errors associated with computational modelling techniques; in particular, that Generalised Gradient Approximation (GGA) functionals in density functional theory (DFT) are known to strongly underestimate band gaps, and electron effective masses are generally underestimated within DFT itself. Still, the error appears to be systematic, meaning this remains a useful tool for comparative screening of materials at the early stages. ${ }^{7}$

\subsection{Group IIIA- and IIIB-doped $\mathrm{ZnO}$}

2.2.1 Aluminium and gallium. Zinc oxide is a non-toxic, refractory, hexagonal wurtzite-type semiconductor with a wide direct band gap of $3.37 \mathrm{eV},{ }^{71}$ as well as being thermally and chemically stable under hydrogen plasma conditions used in solar cell production. ${ }^{72}$ Crucially however, zinc and oxygen are two of the most abundant elements in the earth's crust, present at $70 \mathrm{ppm}$ and $4.61 \times 10^{5} \mathrm{ppm}$ for $\mathrm{Zn}$ and $\mathrm{O}$ respectively; 


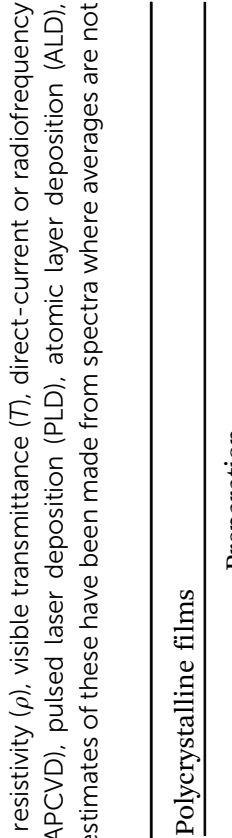<smiles>C=CC</smiles>

棺

.

खें

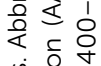

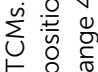

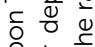

离 言

बें

है.

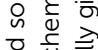

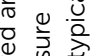

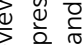

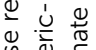

단

元

产 $\frac{\sigma}{0} \frac{0}{\pi}$

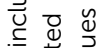

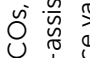

>

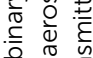

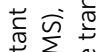

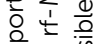

$\underline{\xi} \dot{0}$

है $\sum_{\Sigma}^{\infty}$

它

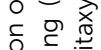

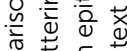

है 흥 $\frac{\varepsilon}{0}$

ن 0 ○

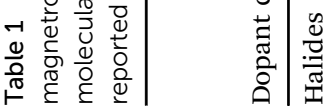

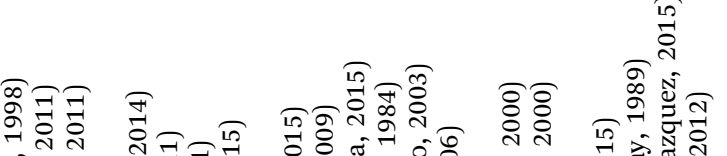

㲾言

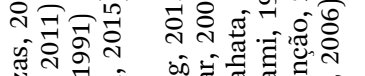

这运

त्र

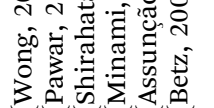

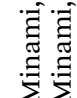

of

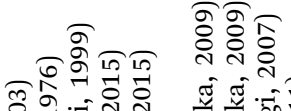

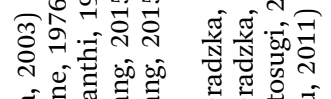

셍

의유캉

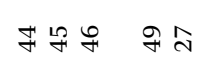

กิ

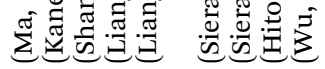

ำ 윰요

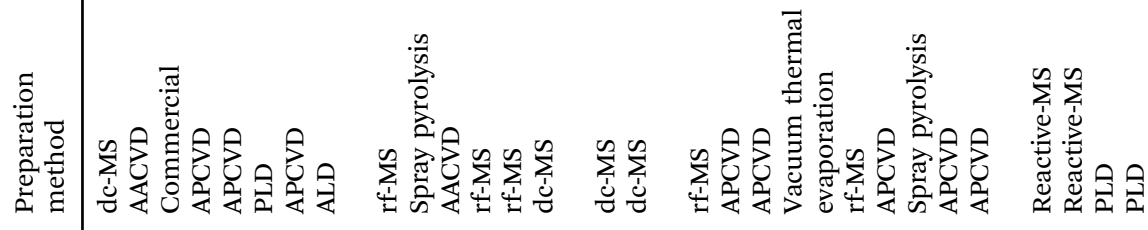

其

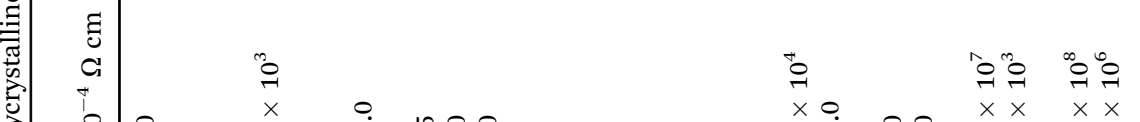

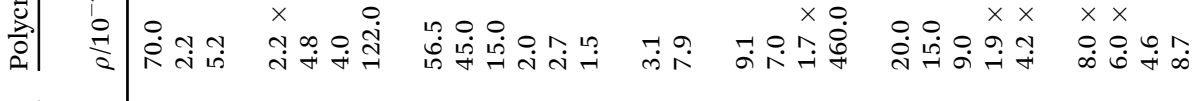

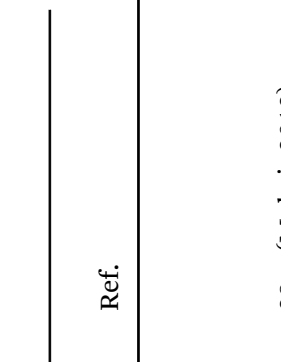

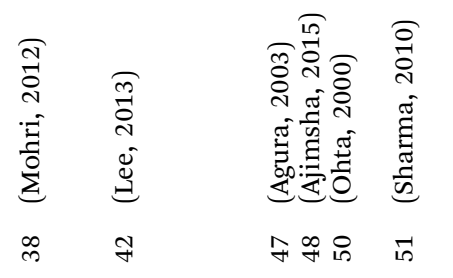

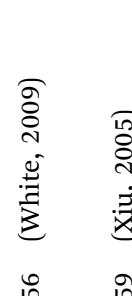

莫

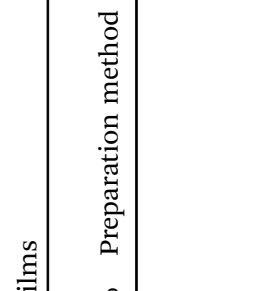

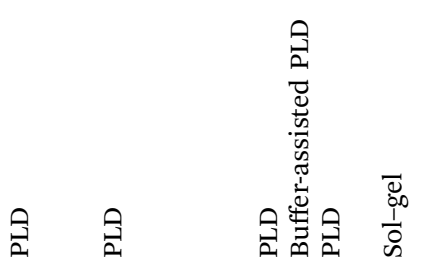

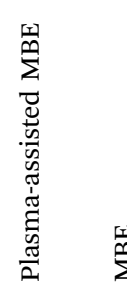

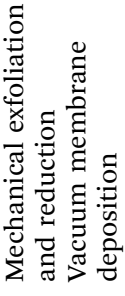

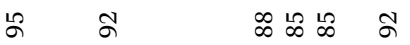

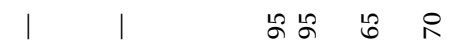

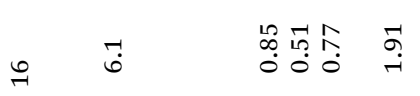

$\hat{\wp}$

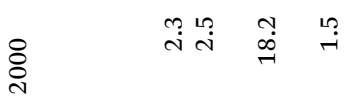

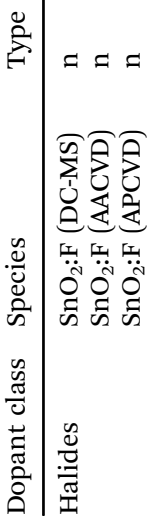

$a \approx \approx \approx$

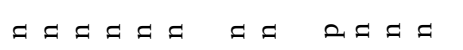

目东

के है

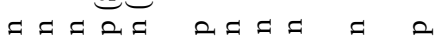

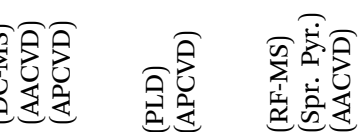

会完灾

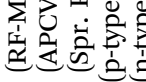

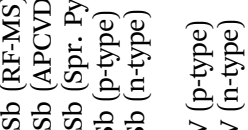

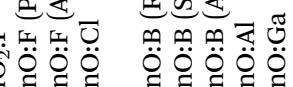

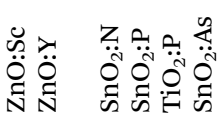

ठैं की की

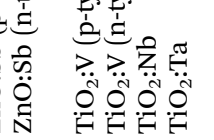

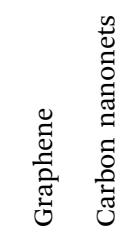

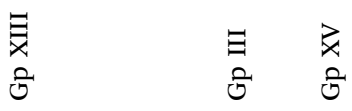

$\begin{array}{ll}\text { 0ี } & \text { ป }\end{array}$ 
indium on the other hand has an elemental abundance in the earth's crust of just $0.25 \mathrm{ppm}^{73}$ Also known as AZOs, aluminium-doped zinc oxides have arisen as an earth-abundant alternative to ITO. In the mid-1990s, Islam et al. synthesised some of the earliest transparent conductive AZO films, which exhibited resistivities of $2.2 \times 10^{-4} \Omega \mathrm{cm} v s .3 .2 \times 10^{-3} \Omega \mathrm{cm}$ for the Al-doped and undoped $\mathrm{ZnO}$ respectively, as synthesised by spray pyrolysis. ${ }^{74}$ It had long been known that introduction of impurities or vacancies into $\mathrm{ZnO}$ conferred conductivity to the transparent film, ${ }^{75}$ however it was only in the 1990 s that its practical potential as a TCO material had begun to be explored. By the year 2000, it had been found that $\mathrm{Al}$ and $\mathrm{Ga}$ dopants in ZnO produced the lowest resistivities, which by this point were down to $1.4 \times 10^{-4} \Omega \mathrm{cm}$ and $1.2 \times 10^{-4} \Omega \mathrm{cm}$ respectively, as compared with other dopants such as B, Y, In, Sc, Si, Ge, Ti, Zr, $\mathrm{Hf}$ and $\mathrm{F}^{76,77}$ Both the $\mathrm{AZO}$ ( $\mathrm{ZnO}: \mathrm{Al}, 1.6-3.2$ at\% $\mathrm{Al}$ ) and $\mathrm{GZO}$ (ZnO:Ga, 1.7-6.1 at\% Ga) n-type materials had carrier concentrations of approximately $1.5 \times 10^{21} \mathrm{~cm}^{-3}$, as compared with concentrations of around $0.5 \times 10^{21} \mathrm{~cm}^{-3}$ for the other listed doped materials. Resistivities of polycrystalline AZO and GZO films have improved little since then. The best quality polycrystalline ITO films synthesised by magnetron sputtering methods typically have resistivities of around $1-2 \times 10^{-4} \Omega \mathrm{cm}$ with carrier concentrations of around $10^{21} \mathrm{~cm}^{-3}$ and no colouring. ${ }^{27,30}$

GZOs have attracted particular attention due to the close matching of $\mathrm{Ga}^{3+}$ and $\mathrm{Zn}^{2+}$ ionic radii, while $\mathrm{Ga}$ also effects a lower electron effective mass in the TCO (see Fig. 8); both of these factors are therefore more likely to result in higher electron mobilities in n-type GZO TCOs. However, while GZO and AZO films are competitive with each other in terms of TCO properties, the affordability and natural abundance of Al makes this a particularly attractive dopant material in TCO production, whereas in 2014 the supply risk of Ga was closely comparable with that of In (see Fig. 6). ${ }^{69}$

AZOs have been synthesised by a number of means including atmospheric-pressure (thermal) chemical vapour deposition, ${ }^{72} \mathrm{RF}$ and DC magnetron sputtering, ${ }^{78,79}$ atomic layer deposition, ${ }^{80}$ pulsed laser deposition, ${ }^{81}$ sol-gel ${ }^{82}$ and spray pyrolysis techniques. ${ }^{71}$ AZOs, like any trivalent-doped n-type $\mathrm{ZnO}$ TCO, work by substituting an $\mathrm{Al}^{3+}$ ion into $\mathrm{Zn}^{2+}$ site, leaving an excess electron at the substituted site and therefore leading to n-type conductivity. In principle, the conductivity of the doped films can therefore be improved by increasing the dopant concentration (and therefore the free carrier concentration). However, the trouble with minimising resistivity by ramping up the carrier concentration is that having a carrier concentration anywhere over $c a .2 \times 10^{21} \mathrm{~cm}^{-3}$ causes a shift of the plasma edge in the absorption spectrum from the infrared into the visible region, resulting in coloured films in extreme cases, ${ }^{31}$ while also reducing the free carrier relaxation time due to an increase in the concentration of scattering sites. The negative impact on resistivity and optical transmission of increasing the dopant concentration beyond its optimum is similar to that of increasing film thickness (Fig. 4), since an increased number of scattering sites and charge carriers leads to decreased mobility and a more pronounced free carrier absorption (FCA) effect.

Perhaps the upper limit of a TCO's potential optoelectronic properties can be represented by the monocrystalline film, in which the major obstacle to carrier mobility is simply the dopant concentration rather than the grain boundaries, the latter being the case with the more practical polycrystalline films. A comparison of the conductivities of epitaxially-grown monocrystalline TCOs is given in Fig. 9, while the polycrystalline films are compared in Fig. 10. Monocrystalline AZO grown epitaxially using

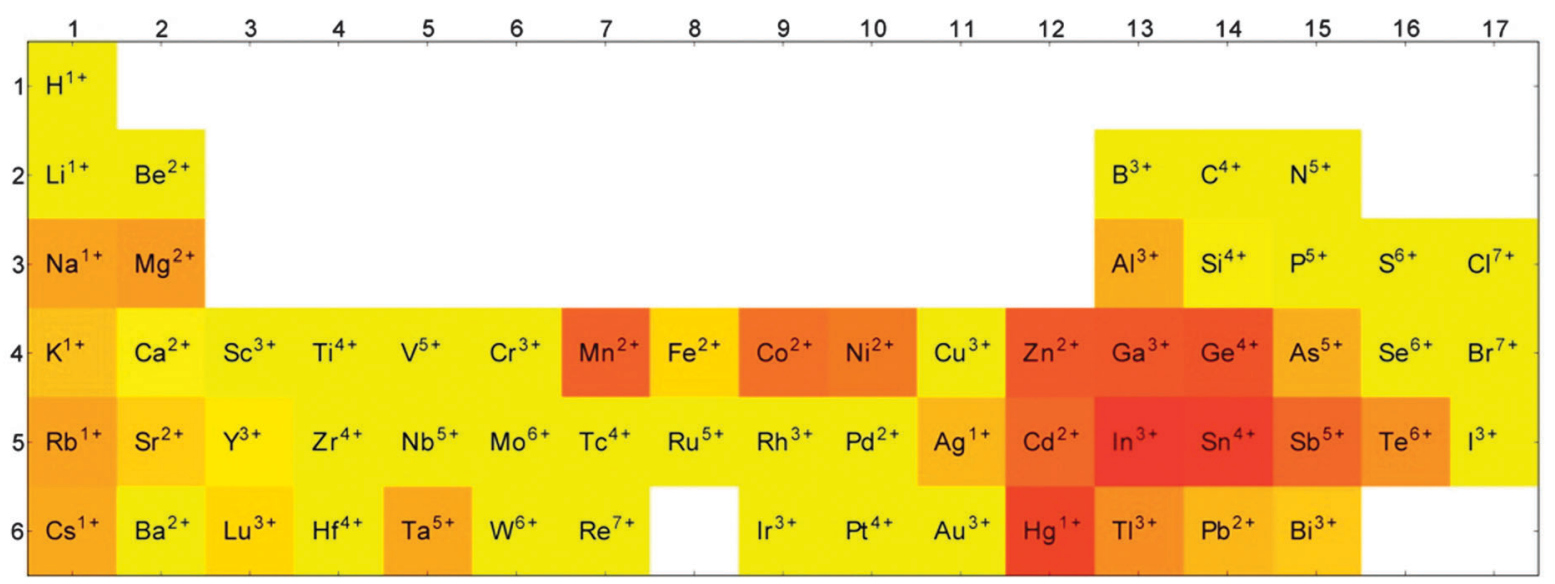

electron effective mass

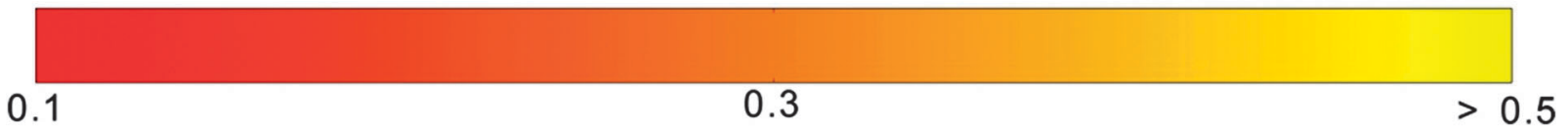

Fig. 8 Computation of the elements which exhibit the lowest electron effective masses in their respective binary oxides. Adapted with permission from Hautier et al. ${ }^{7}$ Copyright 2014 American Chemical Society. 


\section{Epitaxially-grown TCOs}

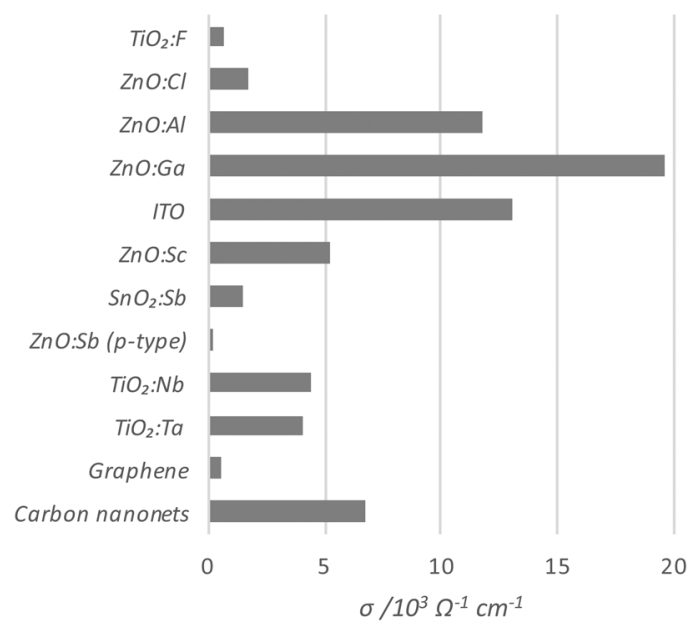

Fig. 9 Comparison of conductivities of epitaxially-grown monocrystalline transparent conducting oxides, as compared with current conventional carbon-based TCMs. The full data set with author references is given in Table 1.

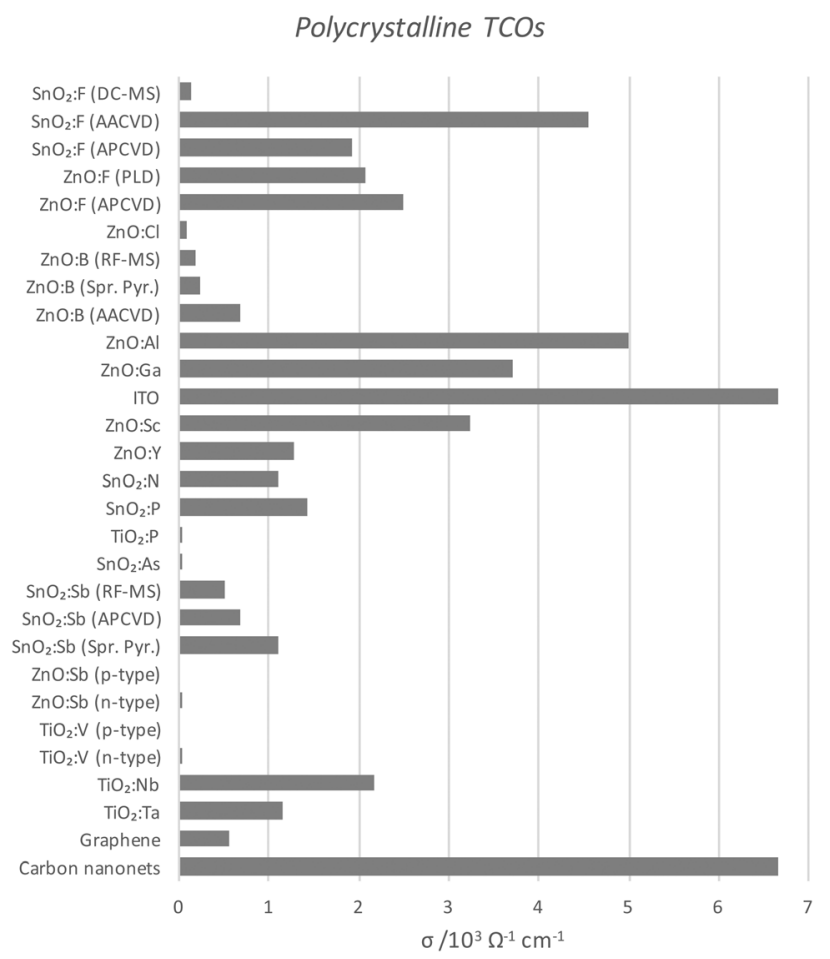

Fig. 10 Comparison of conductivities of polycrystalline TCOs deposited by various means, as also compared with current carbon TCMs. The full data set with author references is given in Table 1. Abbreviations: aerosol-assisted or atmospheric pressure chemical vapour deposition (AA- or AP-CVD), radiofrequency or direct current magnetron sputtering (RF- or DC-MS), spray pyrolysis (Spr. Pyr.).

pulsed laser deposition (PLD) exhibits a resistivity of $\rho=$ $8.5 \times 10^{-5} \Omega \mathrm{cm} ;{ }^{47}$ polycrystalline AZO has been deposited by $\mathrm{RF}$ magnetron sputtering (rf-MS) with around $\rho=2 \times 10^{-4} \Omega \mathrm{cm}^{70}$ Commercial polycrystalline ITO grown by DC magnetron sputtering (dc-MS) typically exhibits $\rho=1.5 \times 10^{-4} \Omega \mathrm{cm},{ }^{27}$ so from this point of view, AZO appears to be a very competitive alternative. However, an issue encountered in the past with magnetron sputtering deposition of electrically conductive doped $\mathrm{ZnO}$ films has been the relative sensitivity of $\mathrm{Zn}$ to the strength of the oxidising environment in which the films are deposited, on account of the increased chemical activity of $\mathrm{Zn}$ in such environments as compared with deposition of In or Sn oxides. The result is an uneven distribution of electrical conductivity in large-area AZO films, which places limitations on their utility. ${ }^{76}$

It is important to note that, while epitaxial methods for growing films on crystalline substrates are useful for demonstrating the upper limits of the properties of a particular TCO material, most industrial deposition techniques are more likely to yield polycrystalline films, in particular atmospheric-pressure (thermal) chemical vapour deposition (APCVD) and dc-MS. By its nature, PLD is generally not easily scalable for industrial largearea film deposition where hundreds of square metres rather than a few square centimetres need to be covered at an appreciable rate of film growth. ${ }^{83}$ Therefore, while epitaxial PLD films may be representative of the ideal case for a film, providing an upper limit to the properties achievable for a given TCO formula, it is perhaps more useful for us to compare the properties of TCOs deposited by scalable methods such as APCVD or magnetron sputtering.

2.2.2 Scandium and yttrium. Group IIIB metal-doped films such as $\mathrm{ZnO}:(\mathrm{Sc}, \mathrm{Y})$ have been investigated in recent years, deposited by magnetron sputtering and yielding good optoelectronic properties; for ZnO:Sc and ZnO:Y respectively, $\rho=3.1 \times 10^{-4} \Omega \mathrm{cm}$ and $7.9 \times 10^{-4} \Omega \mathrm{cm}$ with $\sim 85 \%$ visible transmittance for each. ${ }^{52}$ The discrepancy between the two is thought to be due to the closer matching between ionic radii of $\mathrm{Sc}^{3+}$ with $\mathrm{Zn}^{2+}$ as compared with $\mathrm{Y}^{3+}$ (see Table 2). ${ }^{52}$ While the majority of the rare earth metals are considered to have a high supply risk, Sc metal is thought to be the exception. ${ }^{69}$ It is likely that the lesser interest in $\mathrm{ZnO}: \mathrm{Sc}$ as compared with other trivalent-doped n-type TCOs is due to the apparently superior properties of the cheaper and more widely available $\mathrm{ZnO}: \mathrm{Al}$.

\subsection{Group VA- and VB-doped $\mathrm{TiO}_{2}$ and $\mathrm{SnO}_{2}$}

2.3.1 Tantalum and niobium. As well as to maximise optical transmittance and charge carrier mobility, the search for new TCO materials also seeks to optimise efficiency in cases such as solar cells, in which proper band alignment with the existing active components is highly desirable. $\mathrm{TiO}_{2}$, while possessing unfavourably high electron effective masses (see Fig. 8), is known for its chemical stability in a reducing atmosphere, whilst its thin films are also largely transparent to visible light. Crucially however, it is commonly employed as a photoanode in dyesensitised solar cells for its band alignment with the active components of the cell. ${ }^{84}$

Recent work has found that substitution of Ti atoms in the anatase $\mathrm{TiO}_{2}$ tetragonal cell with group VB metal atoms such as $\mathrm{Nb}$ or Ta transforms the intrinsically semiconducting $\mathrm{TiO}_{2}$ into an effective TCO with previously recorded resistivities reaching 
Table 2 Ionic radii of TCO host ions and common dopants, for given oxidation states (O.S.) and coordination numbers (C.N.). Data from Ginley et al. ${ }^{30}$ and Shannon \& Prewitt ${ }^{85}$

\begin{tabular}{|c|c|c|c|c|}
\hline Class & Element & O.S. & C.N. & Ionic radius/Å \\
\hline \multirow[t]{4}{*}{ Host } & $\mathrm{O}$ & -2 & $2 / 3 / 4$ & 1.4 \\
\hline & $\mathrm{Sn}$ & +4 & 6 & 0.69 \\
\hline & $\mathrm{Zn}$ & +2 & 4 & 0.60 \\
\hline & $\mathrm{Ti}$ & +4 & 6 & 0.61 \\
\hline \multirow[t]{2}{*}{ Halides } & $\mathrm{F}$ & -1 & $2 / 3 / 4$ & 1.3 \\
\hline & $\mathrm{Cl}$ & -1 & 4 & 1.81 \\
\hline \multirow[t]{4}{*}{ Gp XIII } & B & +3 & 4 & 0.12 \\
\hline & $\mathrm{Al}$ & +3 & 4 & 0.39 \\
\hline & $\mathrm{Ga}$ & +3 & 4 & 0.47 \\
\hline & In & +3 & 6 & 0.79 \\
\hline \multirow[t]{2}{*}{ Gp III } & $\mathrm{Sc}$ & +3 & 6 & 0.73 \\
\hline & $\mathrm{Y}$ & +3 & 6 & 0.89 \\
\hline \multirow[t]{5}{*}{ Gp XV } & $\mathrm{N}$ & -3 & 4 & 1.32 \\
\hline & $P$ & +5 & 4 & 0.17 \\
\hline & As & +5 & 6 & 0.50 \\
\hline & $\mathrm{Sb}$ & +3 & 4 & 0.77 \\
\hline & $\mathrm{Sb}$ & +5 & 6 & 0.61 \\
\hline \multirow[t]{4}{*}{ Gp V } & V & +3 & 6 & 0.64 \\
\hline & V & +5 & 6 & 0.54 \\
\hline & $\mathrm{Nb}$ & +5 & 6 & 0.64 \\
\hline & $\mathrm{Ta}$ & +5 & 6 & 0.64 \\
\hline
\end{tabular}

as low as $\rho=2-3 \times 10^{-4} \Omega \mathrm{cm}$ for both the Ta- and Nb-doped anatase films epitaxially grown by PLD, ${ }^{62}$ while the best apparent polycrystalline films synthesised have $\rho=4.6 \times 10^{-4} \Omega \mathrm{cm}$ and $8.7 \times 10^{-4} \Omega \mathrm{cm}$ for $\mathrm{TiO}_{2}: \mathrm{Nb}$ and $\mathrm{TiO}_{2}: \mathrm{Ta}$ respectively. ${ }^{63,65}$ Computational studies have disagreed on which of $\mathrm{Ta}$ or $\mathrm{Nb}$ shows more promise as a dopant in anatase $\mathrm{TiO}_{2}$, since while the two have similar ionic radii (see Table 2), the studies differ on the discussion of Ta doping. On the one hand, Ta is reported to effect a greater local distortion of the crystal lattice than $\mathrm{Nb}$, potentially impeding both charge carrier mobility and crystal growth; on the other hand, Ta is also reported to have both higher solubility in anatase than $\mathrm{Nb}$ and a lower effective mass band structure (see Fig. 8), which leads to increased mobilities. ${ }^{9,86}$ In any case, in spite of $\mathrm{TiO}_{2}:(\mathrm{Nb}, \mathrm{Ta})$ having very similar properties in the epitaxial films, experimental results consistently indicate that the Nb-doped $\mathrm{TiO}_{2}$ are the better-performing of the polycrystalline films; the fact that $\mathrm{TiO}_{2}: \mathrm{Nb}$ accounts for a significantly greater portion of recent research than its Ta-doped counterpart is reflective of this. ${ }^{84}$ However, while $\mathrm{Nb}$ is considered by the European Commission to have a critical supply risk (greater even than In), Ta was removed in 2013 from the category due to a reduction in the supply risk, on account of increased global supply from Australia and, more recently, Brazil. ${ }^{69}$

The earliest examples of studies detailing the syntheses of $\mathrm{TiO}_{2}: \mathrm{Ta}$ and $\mathrm{TiO}_{2}: \mathrm{Nb}$ are a pair of 2005 papers in which the films were grown epitaxially on $\mathrm{SrTiO}_{3}$ (001) and $\mathrm{LaAlO}_{3}(001)$ crystalline substrates by PLD. ${ }^{62,64}$ These films formed a new class of TCO whose conductivity was dependent on d-electrons, in contrast to typical TCO materials in which s- or p-electrons are more commonly responsible for conductivity, ${ }^{64}$ due to $\mathrm{TiO}_{2}$
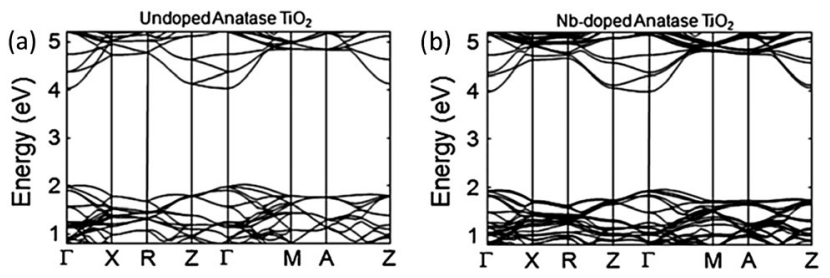

Fig. 11 Calculated electronic band structures of (a) $\mathrm{TiO}_{2}$ and (b) $\mathrm{TiO}_{2}: \mathrm{Nb}$. The Brillouin zone centre is denoted by $\Gamma$, while $X, R, Z, M$ and $A$ denote points at the Brillouin surface along high symmetry $k$-vectors in the reciprocal crystal lattice. The lines represent allowed electronic energy states at given $k$-points. Adapted with permission from Hitosugi et al. ${ }^{89}$ Copyright 2008 The Japan Society of Applied Physics.

being the only widely investigated transition-metal-oxide (i.e. d-block) host material for TCOs. It is thought that the spins associated with d-electrons may lead to new applications for this class of TCOs in spintronic devices. ${ }^{87}$

One issue with $\mathrm{Ti}_{1-x} \mathrm{Nb}_{x} \mathrm{O}_{2}$ is the strong optical absorption in the red proportional to dopant concentrations over approximately $x=0.03$. The result is strongly blue-coloured films. ${ }^{62,88,89}$ The origin of this effect is the narrow band gap between the occupied CBM and CBM + 1 in the doped films, which is evident in Fig. 11, giving rise to a pronounced free carrier absorption (FCA) effect. ${ }^{89}$ Unfortunately, in order that polycrystalline $\mathrm{Ti}_{1-x} \mathrm{Nb}_{x} \mathrm{O}_{2}$ should have competitive resistivities (i.e., $\rho<10^{-3} \Omega \mathrm{cm}$ ), it is necessary to have $x \geq 0.06$, which gives rise to a significant blue colouration effect. ${ }^{63,88}$ This is a desirable property in certain applications such as some window coatings, however it does preclude the use of $\mathrm{TiO}_{2}: \mathrm{Nb}$ TCOs in applications where transmission of a full visible spectrum is required e.g. mainstream flat panel displays (FPDs). In general, $\mathrm{TiO}_{2}$-based TCOs tend to possess a high refractive index, which has also been linked to colouration due to intrinsic interference effects. ${ }^{87}$ On the other hand, a reduced optical band gap appears to be preferable in photocatalytic applications, in which the absorption of light both in the UV and in the visible promotes catalytic efficiency. Certain circumstances may therefore call for a film which is at once transparent, conducting and photocatalytically active. Indeed, much research presently investigates the doping of $\mathrm{TiO}_{2}$ in order to increase photocatalytic activity by absorption of visible light. ${ }^{90,91}$

In the case of Ta-doped $\mathrm{SnO}_{2}$, while the low electron effective masses in the $\mathrm{SnO}_{2}$ host are attractive (see Fig. 8), the ability to tailor conductivity of $\mathrm{SnO}_{2}$ :Ta by varying dopant levels is restricted somewhat by the thermodynamic competition of the pseudobinary phase $\mathrm{SnO}_{2}: \mathrm{TaO}_{2}$ with the ternary phase $\mathrm{SnTa}_{2} \mathrm{O}_{6}$, as well as the trapping of electrons at $\mathrm{Ta}^{5+}$ sites due to local Jahn-Teller distortion, also associated with high dopant levels. A combination of these two key factors places an upper limit on the conductivity of $\mathrm{SnO}_{2}: \mathrm{Ta}$, with a maximum conductivity predicted using firstprinciples computation at a dopant concentration of approximately 1 at $\% \mathrm{Ta}$. The same is also true of $\mathrm{Nb}$-doped $\mathrm{SnO}_{2}$, where the optimal doping level lies around 2 at $\% \mathrm{Nb}^{.92}$

2.3.2 Phosphorus and antimony. Other pentavalent cations such as $\mathrm{P}^{5+}$ and $\mathrm{Sb}^{5+}$ have also been used as substitutional dopants in TCO materials. For instance, $\mathrm{SnO}_{2}: \mathrm{Sb}$ (ATO) has been studied 
since the 1970s, far longer than the Ta or Nb-doped $\mathrm{SnO}_{2}$, which have only become apparent as viable TCO materials within the past decade. ATO is interesting in part because its optical absorption profile is relatively broad, typically dropping below $80 \%$ transmission only above wavelengths of $1500 \mathrm{~nm},,^{93}$ - this is contrast to other popular TCOs such as FTO, ${ }^{94}$ ITO $^{95}$ and AZO, ${ }^{47}$ which all see transmission fall dramatically above $1000 \mathrm{~nm}$, and which usually have $<10 \%$ transmission at $1500 \mathrm{~nm}$ in the cases of ITO and AZO, and 30\% in FTO. ATO may find its niche on account of this. One of the best-performing polycrystalline $\mathrm{SnO}_{2}: \mathrm{Sb}$ films reported was deposited by spray pyrolysis by Shanthi et al. in $1999\left(\rho=9.0 \times 10^{-4} \Omega \mathrm{cm}\right) .{ }^{29}$ Other studies have deposited good quality polycrystalline ATO by RF magnetron sputtering $^{57}$ and APCVD. ${ }^{58}$ Monocrystalline ATO films have reached $\rho=6.7 \times 10^{-4} \Omega \mathrm{cm}$, as deposited by molecular beam epitaxy (MBE).$^{56}$ These values indicate that, while being workable TCOs, ATOs are not as competitive with ITO or AZOs in terms of conductivity, but its characteristically high optical transmission at long wavelengths could lead to special applications for ATO such as antireflective coatings, akin to AgO films. ${ }^{96}$ Another application in which ATO has performed notably well is the sensing of ethanol, due to quick response and recovery times. ${ }^{97}$ While ATO is a widely used TCO material, antimony also suffers similarly to indium in terms of its supply risk (see Fig. 6). In contrast to $\mathrm{SnO}_{2}$ : $\mathrm{Sb}$, antimony-doped $\mathrm{ZnO}$, like other group VA-doped ZnO TCOs, suffers from self-compensation of native point defects $\mathrm{V}_{\mathrm{O}}$ and $\mathrm{Zn}_{\mathrm{i}}$, meaning control over $\mathrm{p}$ - or n-type conduction is complicated by its preparation conditions and often leads to internal neutralisation of charge carriers (see Fig. 12). Because of this, $\mathrm{ZnO}: \mathrm{Sb}$ does not exhibit resistivities which are competitive with other modern TCO formulations ( $\rho=4184 \Omega \mathrm{cm}$ for n-type $\mathrm{ZnO}: \mathrm{Sb}) .{ }^{60}$

Perhaps more electrically competitive is the arsenic-doped $\mathrm{SnO}_{2}$ :As, which was deposited in the late 1980s via APCVD to yield films which claimed $\rho=1.5 \times 10^{-4} \Omega \mathrm{cm},{ }^{98}$ although efforts since then have been unable to achieve such low resistivity. ${ }^{55}$ Around the same time, that group found that $\mathrm{SnO}_{2}: \mathrm{P}$ deposited in a similar manner was capable of $\rho=7.0 \times 10^{-4} \Omega \mathrm{cm} .{ }^{53}$

A recent computational study has found that of the group VA dopants ( $\mathrm{P}, \mathrm{As}, \mathrm{Sb}, \mathrm{Bi})$ in $\mathrm{SnO}_{2}$, only $\mathrm{P}$ and $\mathrm{Sb}$ are effective n-type donors due to the change in oxidation state from $\mathrm{V}$ to III of As and $\mathrm{Bi}$ substituted sites as the Fermi level approaches
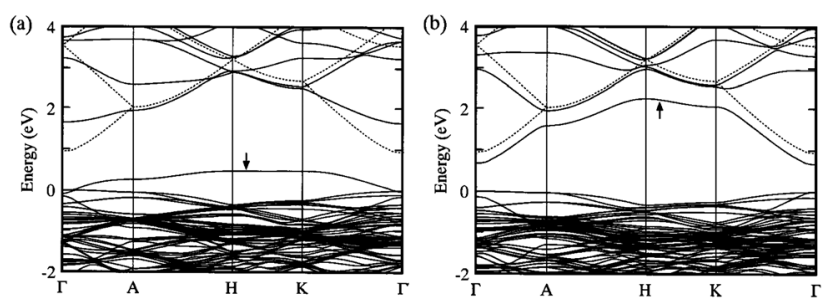

Fig. 12 Calculated band structure for $\mathrm{ZnO}$ supercells with (a) oxygen vacancy and (b) zinc interstitial. Note the direct competition of (a) p-type and (b) n-type conductivity between the two defect species. The valence band maximum is defined at zero energy. The highest occupied state is indicated by an arrow in each. Adapted with permission from Oba et al. ${ }^{99}$ Copyright 2001 AIP Publishing LLC. the CBM. ${ }^{8,100}$ However, another experimental study has shown that $\mathrm{P}$ can also exhibit multiple oxidation states (namely $\mathrm{P}^{5+}$ and $\mathrm{P}^{3-}$ ) in a $\mathrm{TiO}_{2}: \mathrm{P}$ TCO depending on the conditions of the deposition, and that $\mathrm{P}^{3-}$ incorporation is overall detrimental to its electronic and photocatalytic properties. ${ }^{54}$

2.3.3 Nitrogen doping. Amongst the group VA dopants, nitrogen-doped $\mathrm{SnO}_{2}$ films behave differently to $\mathrm{SnO}_{2}:(\mathrm{P}, \mathrm{Sb}$ or As), due to the anionic nature of the dopant; $\mathrm{N}^{3-}$ is thermodynamically favourable on an $\mathrm{O}^{2-}$ lattice site, when compared with $\mathrm{N}^{5+}$ on an $\mathrm{Sn}^{4+}$ site. As such, $\mathrm{SnO}_{2}$ : $\mathrm{N}$ films tend to adopt p-type behaviour, rather than the n-type conductivity observed in $\mathrm{SnO}_{2}$ films substituted with pentavalent cations. Such films have been synthesised recently; $\mathrm{SnO}_{2}: \mathrm{N}$ thin films deposited via $\mathrm{RF}$ magnetron-sputtering on heated substrates (quartz, $400{ }^{\circ} \mathrm{C}$ ) are polycrystalline and somewhat conductive $\left(\rho=5.86 \times 10^{-3} \Omega \mathrm{cm}\right) .{ }^{101}$ Curiously however, the same group found that low-temperature deposition by similar means upon an unheated PET polymer substrate yields an amorphous film with electronic properties superior to those of the polycrystalline film $(\rho=9.1 \times$ $10^{-4} \Omega \mathrm{cm}$ ), with similar optical transmittance around $80 \% .^{33}$ This breaks the trend for TCO materials, in which a higher degree of crystallinity usually results in improved optoelectronic properties. ${ }^{65,84,86,87}$ The discrepancy in the case of $\mathrm{SnO}_{2}: \mathrm{N}$ could be a result of difficulties faced by other groups in synthesising crystalline p-type nitrogen-doped TCOs in the past, where self-compensation of $\mathrm{N}_{\mathrm{O}}$ (p-type) with diatomic $(\mathrm{NN})_{\mathrm{O}}$ and $\mathrm{V}_{\mathrm{O}}$ (n-type) substitutional dopants in the TCO leads to competition between $\mathrm{p}$-type or n-type conductivity, hindering preference for either and resulting in a carrier concentration three to six orders of magnitude lower than the dopant concentration. ${ }^{102}$ Indeed, one study directly observed that increasing the annealing temperature of amorphous $\mathrm{Sn}_{3} \mathrm{~N}_{4}$, while producing more highly crystalline films, resulted in a gradual decrease of conductivity. ${ }^{103}$

\subsection{Halide dopants}

Unlike cation dopants which substitute metal ion sites, halide dopants substitute at the oxygen sites and are therefore more widely dopable into metal-oxide TCO hosts to produce n-type $\mathrm{SnO}_{2}: \mathrm{F}, \mathrm{ZnO}: \mathrm{F}$ and $\mathrm{TiO}_{2}: \mathrm{F} \cdot{ }^{37,38,41}$ The most widespread TCO material containing a halide dopant is fluorine-doped tin oxide (FTO), which is widely produced industrially as an important low-emissivity window coating due to its reflectivity in the infrared region (see Fig. 13). Of the halides, $\mathrm{F}^{-}$is the most effective dopant for TCOs due to its excellent matching of the $\mathrm{O}^{2-}$ ionic radius (see Table 2). For this reason, larger halide dopants such as $\mathrm{Cl}^{-}$are less stable substitutional defects in a metal oxide crystal on account of the exertion of strain on the local environment - such strains restrict charge carrier mobility and phonon propagation, as well as encouraging unstable interstitial $\mathrm{Cl}^{-}$and thermal ion migration. ${ }^{43}$ FTO is therefore the favoured halide-doped TCO, with excellent thermal and chemical stability, transmissivity in the visible exceeding $85 \%$, excellent IR reflectivity as well as being inexpensive and chemically robust. ${ }^{36,37,104}$

The most electrically conducting FTO thin film deposited by magnetron sputtering methods has achieved $7.0 \times 10^{-3} \Omega \mathrm{cm},{ }^{36}$ 


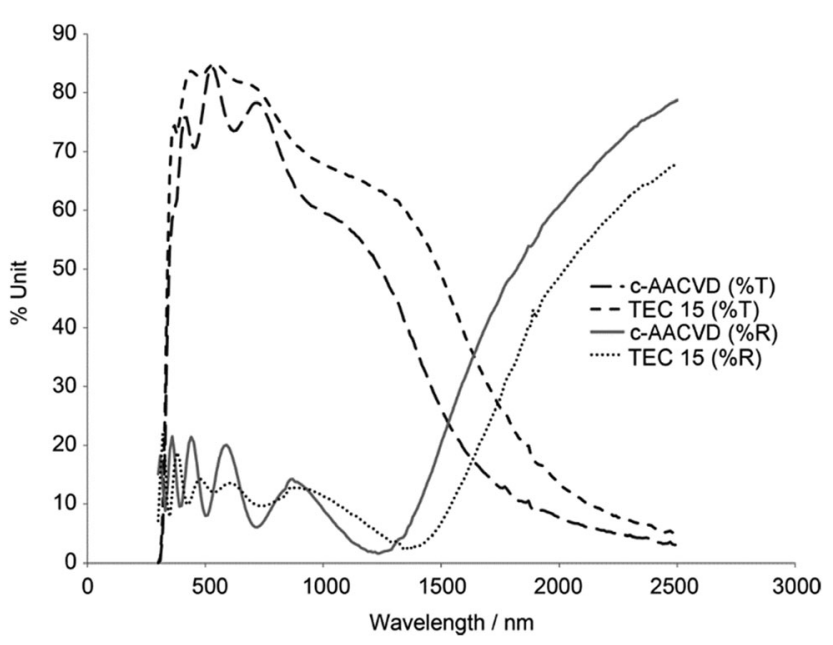

Fig. 13 Optical transmittance $(\% T)$ and reflectance $(\% R)$ spectra of $\mathrm{SnO}_{2}: \mathrm{F}$ lab-grown by combinatorial aerosol-assisted chemical vapour deposition (c-AACVD) as compared with an industrial $\mathrm{SnO}_{2}: \mathrm{F}$ product (TEC 15, Pilkington NSG). Adapted with permission from Bhachu et al. ${ }^{37}$ Copyright 2011 Wiley.

though in more recent years, aerosol-assisted chemical vapour deposition methods have reached resistivities an order of magnitude lower, down to $2.2 \times 10^{-4} \Omega \mathrm{cm} .{ }^{37}$ Currently one of the best-performing mass-produced FTO thin films on the market, as delivered by on-line atmospheric-pressure CVD (APCVD), is TEC-8 (Pilkington NSG) with $\rho=5.2 \times 10^{-4} \Omega \mathrm{cm} .{ }^{37}$ The generation of aerosols in AACVD as a means of precursor transport has shown much promise in recent years as an alternative to 'traditional' thermal- or AP-CVD, which requires that the precursor has sufficient vapour pressure in order to be transported in the vapour phase. ${ }^{105,106}$ By instead generating an aerosol from the precursor, the vapour pressure requirement is sidestepped as well as producing some interesting morphologies, and therefore properties, in the deposited films. ${ }^{37}$ FTO studies in recent years have therefore investigated alternatives to the commercial APCVD process such as AACVD ${ }^{37}$ and also spray pyrolysis, ${ }^{104}$ both of which have produced highly competitive FTO films.

More recently, F-doped anatase $\mathrm{TiO}_{2}$ has also attracted some attention, whose mediocre electronic properties $(\rho=1.6 \times$ $10^{-3} \Omega \mathrm{cm}$ in the epitaxial film, ${ }^{38} \rho=2.2 \times 10^{-1} \Omega \mathrm{cm}$ in the polycrystalline film $^{39}$ ) are compensated by its exhibition of promising photocatalytic behaviour. ${ }^{90,91}$ The resistivity of these films is several times higher than $\mathrm{Nb}$ - or Ta-doped anatase, and has been attributed to a combination of the low doping efficiency of $\mathrm{F}$ in anatase (20-30\% for $\mathrm{F}$ compared with $70-100 \%$ for $\mathrm{Nb}$ and Ta in anatase) and the high effective mass of free electrons in an F-doped crystal. It has been postulated that the fluoride sites act to trap the electrons, limiting their mobility. ${ }^{38}$ On the other hand, the $\mathrm{F}$ dopant also serves to narrow the optical band gap by stabilisation of $\mathrm{Ti}^{3+}$ and $\mathrm{V}_{\mathrm{O}}$ sites, producing a donor level at the CBM and limiting electron-hole recombination. This facilitates a broader optical absorption profile, so that the films are able to utilise the visible portion of the spectrum for indoor photocatalytic applications. As such, the $\mathrm{TiO}_{2}: \mathrm{F}$ films have been found to perform significantly better than pure anatase in a photocatalytic test (photoinduced degradation of methylene blue dye). ${ }^{90}$

Also interesting are F-doped ZnO films (FZO), which were successfully deposited by APCVD in the early 1990s with excellent optoelectronic properties $\left(\rho=4.0 \times 10^{-4} \Omega \mathrm{cm}\right.$, mobilities up to $\mu=40 \mathrm{~cm}^{2} \mathrm{~V}^{-1} \mathrm{~s}^{-1}, 90 \%$ visible transmittance, $85 \%$ IR reflectance and up to $90 \%$ quantum efficiency in a-Si solar cells). ${ }^{41}$ The lack of interest into FZOs since then could be due to the far more widespread research into AZOs, which are more competitive as earth-abundant n-type ZnO-based TCOs. On the other hand, recent authors have noted that the shortage in FZO study is in part due to difficulties with finding suitable precursors for FZO deposition. ${ }^{107}$

\subsection{Carbon competitors}

Transparent electrode materials other than TCOs have also arisen in recent years; for instance, atom-thick graphene layers have been used for their similarly excellent optical transmission properties ( $\sim 2.3 \%$ visible light absorbed per graphene layer), their exceedingly high electron mobilities coupled with low carrier concentration $\left(\sim 10^{3}-10^{4} \mathrm{~cm}^{2} \mathrm{~V}^{-1} \mathrm{~s}^{-1} \text { and } \sim 10^{13} \mathrm{~cm}^{-2} \text { respectively }\right)^{108}$ and their mechanical flexibility. Graphene electrodes are operable in a solar cell device under bending at $138^{\circ}$, compared with maximum operable bending angle of $60^{\circ}$ in the more brittle indium tin oxide (ITO) TCO cell. ${ }^{35}$ However, for the sheet resistance of graphene to be competitive with ITO, at least four monolayers of graphene are required, which results in a significant loss of optical transmission in the graphene (typically about $10 \%$ less transmittance than ITO). ${ }^{109}$ Furthermore, optical transmission in the graphene drops off dramatically at light incidence angles greater than about $30^{\circ}$, which is a concern not only for information displays but also for the efficiency of graphene-based organic photovoltaic devices (OPVs), where ITO remains the most effective electrode material, which suffers virtually no drop-off in transmission from an increased incidence angle. ${ }^{109} \mathrm{~A}$ further issue arises in graphene-based OPVs on account of its hydrophobicity; this makes aqueous solution processing problematic, particularly in binding the graphene to the hole-transporting layer (HTL) material poly(3,4-ethylenedioxythiophene):poly(styrene sulfonate) (PEDOT:PSS) which consequently impacts the power conversion efficiency (PCE) of the OPV. ${ }^{110}$ As such, graphene OPVs can only achieve a maximum PCE of approximately $60 \%$ that of ITO-based OPVs. Nevertheless, some work has gone towards resolving this issue by doping the graphene electrode ${ }^{111}$ as well as trialling alternative HTL materials. ${ }^{112}$ Carbon nanonet thin films, on the other hand, comprise stacks of randomly oriented single-walled carbon nanotubes (SWCNTs) to a thickness of approximately $50 \mathrm{~nm}$, which have demonstrated, like graphene TCMs, excellent transmission in the infra-red, while ITO and other TCOs are often reflective in this region; on the other hand, this IR transmissivity comes at the expense of the visible region of the spectrum, in which the carbon-based TCMs have only $\sim 70 \%$ transmittance, compared with $80-95 \%$ visible transmittance in TCOs. Therefore, as it stands, it appears that the carbon-based films might be useful in more niche situations than the TCOs, such as flexible electronics or military applications. ${ }^{67}$ 


\section{Transparent electrodes in application}

Myriad modern devices adopt transparent conducting oxide thin films, in virtually every and any optoelectronic context from solar power generation to information displays. In many of these cases, ITO seems to be the most prevalent TCO material adopted, which is problematic for the reasons discussed thus far, with indium's high supply risk at the fore. It has become generally desirable to move away from ITO and begin adopting alternative TCO materials. However, new demand for TCO development is arising in the field of transparent electronics, in which alternatives to ITO are not only desirable from a cost perspective, but also preferable from the technical perspective.

\subsection{Transparent information displays}

Development in the fields of both transparent conducting thin films and active matrix organic light emitting diode (AMOLED) displays has resulted in their joining to form a new and exciting kind of product: transparent AMOLED displays. While transparent OLED (TOLED) displays have been in development since the mid1990 s, $^{113}$ early devices were comprised of a high work function TCO anode (usually ITO) with a low work function metal cathode (e.g. $\mathrm{Ca}, \mathrm{Au}$ or $\mathrm{Ag}-\mathrm{Mg}$ ) sandwiching an organic semiconductor layer with hole (HTL) and electron (ETL) transport layers in the intermediate (see Fig. 14). However, the adoption of even a thin metallic cathode layer sets an upper limit to the optical transparency of only around $50 \% .{ }^{114}$ While prototype transparent televisions have now been developed and showcased by tech giants such as Samsung, these seem to adopt twin ITO electrodes, ${ }^{115}$ wherein the challenge remains to find a cathode material with comparable optical transmittance and electrical resistivity to ITO but a lower work function for more efficient electron injection. Work is ongoing to meet this challenge; for instance, it has been observed both experimentally $^{116}$ and computationally ${ }^{117}$ that extrinsic doping of zinc oxide with e.g. $\mathrm{Al}$ or $\mathrm{Ga}$, such that the surface charge carrier density is increased, will effectively lower its work function at the interface. Likewise, recent work has also sought to raise the work

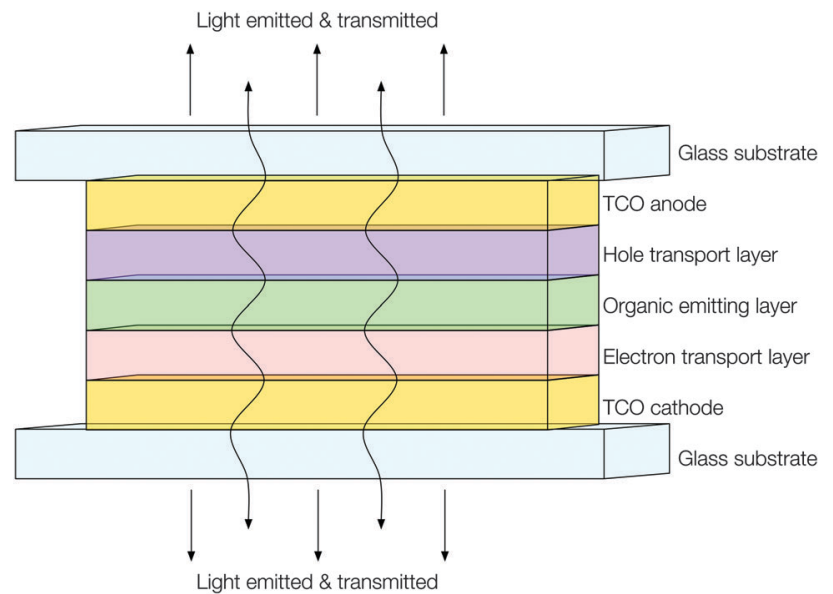

Fig. 14 Schematic illustrating the construction of a transparent AMOLED device adopting TCOs for both electrodes. function of the ITO anode, in order to improve band alignment with the HTL layer and thus overall improve device efficiency. ${ }^{118}$

Aside from this, the usual means of depositing an ITO cathode industrially via sputtering is damaging to the underlying organic layers of the OLED device; ${ }^{119}$ this issue has thus far been addressed by deposition of additional protective buffer layers via e.g. thermal evaporation prior to the sputtering stage, ${ }^{115}$ however this perhaps adds needless complication and expense when an alternative deposition means (e.g. chemical vapour deposition) for the TCO cathode can be sought. Indeed, it has been seen that with many TCO films including $\mathrm{ZnO}: \mathrm{B}, \mathrm{SnO}_{2}: \mathrm{Sb}$ and $\mathrm{SnO}_{2}: \mathrm{F}$, the chemical vapour deposition route will actually often produce films with superior optoelectronic properties to those obtained via sputtering. ${ }^{36,37,44,46,57,58}$

Much has been learned in recent years through computational modelling and experimental verification regarding the tuneability of the work function of doped transparent conducting oxide materials, ${ }^{2,117,118}$ and it is anticipated that the continuing relationship between computational and experimental methods will deliver tangible development to this rapidly evolving field.

\subsection{Transparent photovoltaic cells}

The design of a conventional photovoltaic (PV) cell bears much resemblance to that of an AMOLED device; that is, that a TCO anode is deposited upon a glass substrate, followed by an HTL (e.g. poly(3,4-ethylenedioxythiophene) polystyrene sulfonate, 'PEDOT:PSS'). Upon the HTL is deposited the photoactive layer, which is at last bound directly to a reflective metallic cathode; where a low-work function metallic cathode is used, there is sometimes no need for an intermediary ETL. ${ }^{120}$ Again, ITO is the most commonly adopted TCO anode material in a PV cell, and therefore PV design is yet another technology which stands to benefit from shifting away from ITO towards more affordable and earth-abundant TCO electrodes. But as AMOLED displays now strive for transparency, so too does the conventional PV cell.

By combining solar energy generation with, for example, architectural glass applications, there suddenly arises the exciting new prospect of self-sustaining cities designed and built to meet their own energy demands, or mobile phones which charge themselves in open daylight. True, efficiency in a transparent PV device as compared with an opaque one will inevitably suffer due

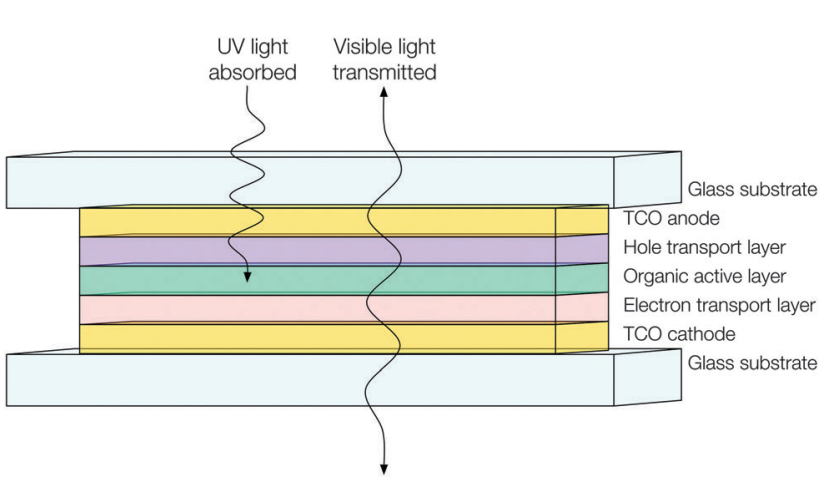

Fig. 15 Schematic of a hypothetical transparent organic photovoltaic device adopting TCO materials for both electrodes. 
to the sacrifice of the visible portion of the spectrum (and therefore the increased dependence on incident UV intensity); however, should these become cheap enough to manufacture, they should be able in principle to become far more pervasive than their opaque analogues due to their ability to be installed almost anywhere and on any device.

Similar technical obstacles face transparent PVs as do TOLEDs - that is, that the metallic cathode ought to be replaced with a highly optically transmissive material with a sufficiently low work function and resistivity so as to facilitate electron injection and distribution (see Fig. 15). Currently transparent PVs appear to be adopting thin metal films for this purpose, which limits their transparency and therefore their utility. ${ }^{121}$ This is just one issue amongst many more which may be tackled by the continued development of n-type doped TCO electrodes, which serves to illustrate the unique utility and value of these ubiquitous and powerful materials.

\section{Summary}

In this state-of-the-art review, both prominent and lesser-known doped binary oxide systems have been reviewed for their utility as transparent conducting electrodes and other important roles. Such materials are of great importance to modern technology, and play a particularly significant role in the global economy. As such, these materials have been considered from both a functional and economic standpoint, given that both factors have equal weight as stimuli for further research. Given the multi-functional roles of these materials, there are a number of factors to be optimised depending on the application; for this reason, there is no 'catch-all' material, and the individual benefits and shortfalls of each material have been discussed, while a more general visual review of about thirty materials compares their resistivities and visible transmittances. The mechanism for the functionality of these materials has been discussed, with regard to the chemical and physical factors which combine to produce the observed phenomena, with particular focus on the now-indispensable dialogue between experimental and computational study. A number of systems have been identified from both computational and experimental studies with potential for further investigation, as well as placing a brief spotlight on some ongoing technological challenges which may yet be solved by further development of transparent conducting oxide thin films.

\section{Acknowledgements}

Mr Alex Ganose is thanked for his assistance with producing Fig. 1. NSG Pilkington Glass and the EPSRC are thanked for their funding through the Molecular Modelling and Material Science $\left(\mathrm{M}^{3} \mathrm{~S}\right)$ Doctoral Training Centre at UCL (EP/G036675) and for grants EP/L017709, EP/K001515 and EP/N01572X.

\section{Notes and references}

1 K. Hayashi, S. Matsuishi, T. Kamiya, M. Hirano and H. Hosono, Nature, 2002, 419, 462-465.
2 A. M. Ganose and D. O. Scanlon, J. Mater. Chem. C, 2016, 4, 1467-1475.

3 E. Burstein, Phys. Rev., 1954, 93, 632-633.

4 D. O. Scanlon and G. W. Watson, J. Mater. Chem., 2012, 22, 25236.

5 A. Walsh, J. Buckeridge, C. R. A. Catlow, A. J. Jackson, T. W. Keal, M. Miskufova, P. Sherwood, S. A. Shevlin, M. B. Watkins, S. M. Woodley and A. A. Sokol, Chem. Mater., 2013, 25, 2924-2926.

6 A. J. Freeman, K. R. Poeppelmeier, T. O. Mason, R. P. H. Chang and T. J. Marks, MRS Bull., 2000, 25, 45-51.

7 G. Hautier, A. Miglio, D. Waroquiers, G.-M. Rignanese and X. Gonze, Chem. Mater., 2014, 26, 5447-5458.

8 D. Cheng, M. Zhang, J. Chen, C. Yang, X. Zeng and D. Cao, J. Phys. Chem. C, 2014, 118, 2037-2043.

9 H. Anh Huy, B. Aradi, T. Frauenheim and P. Deák, J. Appl. Phys., 2012, 112, 016103.

10 P. P. Edwards, A. Porch, M. O. Jones, D. V Morgan and R. M. Perks, Dalton Trans., 2004, 2995.

11 H. Peelaers, E. Kioupakis and C. G. Van de Walle, Appl. Phys. Lett., 2012, 100, 011914.

12 F. L. Wong, M. K. Fung, S. W. Tong, C. S. Lee and S. T. Lee, Thin Solid Films, 2004, 466, 225-230.

13 D. S. Ginley and C. Bright, MRS Bull., 2000, 25, 15-18.

14 J. Cai and L. Qi, Mater. Horiz., 2015, 2, 37-53.

15 Y. Lin, X. Zhang, S. Bai and A. Hu, J. Mater. Chem. C, 2015, 3, 6046-6052.

16 R. B. Fair, Microfluid. Nanofluid., 2007, 3, 245-281.

17 Future Market Insights, Flat Panel Display Market: Global Industry Analysis and Opportunity Assessment 2014-2020, 2015.

18 C. I. Bright, in 50 Years of Vacuum Coating Technology and the Growth of the Society of Vacuum Coaters, ed. D. M. Mattox and V. H. Mattox, Society of Vacuum Coaters, 2007, p. 38.

19 T. M. Letcher and J. L. Scott, Materials for a Sustainable Future, Royal Society of Chemistry, 2012.

20 R. L. Moss, E. Tzimas, H. Kara, P. Willis and J. Kooroshy, Critical Metals in Strategic Energy Technologies, 2011.

21 M. Grundmann, Phys. Status Solidi, 2015, 212, 1409-1426.

22 A. Wang, J. R. Babcock, N. L. Edleman, A. W. Metz, M. A. Lane, R. Asahi, V. P. Dravid, C. R. Kannewurf, A. J. Freeman and T. J. Marks, Proc. Natl. Acad. Sci. U. S. A., 2001, 98, 7113-7116.

23 H. Mcmaster, US Pat., 2429420, 1947.

24 G. Rupprecht, Z. Phys., 1954, 139, 504-517.

25 T. Minami, Appl. Phys. Lett., 1982, 41, 958.

26 S. Major, A. Banerjee and K. L. Chopra, Thin Solid Films, 1983, 108, 333-340.

27 U. Betz, M. Kharrazi Olsson, J. Marthy, M. F. Escolá and F. Atamny, Surf. Coat. Technol., 2006, 200, 5751-5759.

28 J.-A. Jeong, J. Lee, H. Kim, H.-K. Kim and S.-I. Na, Sol. Energy Mater. Sol. Cells, 2010, 94, 1840-1844.

29 S. Shanthi, C. Subramanian and P. Ramasamy, J. Cryst. Growth, 1999, 197, 858-864.

30 D. S. Ginley, H. Hosono and D. C. Paine, Handbook of Transparent Conductors, 2010. 
31 C. Guillén and J. Herrero, Thin Solid Films, 2011, 520, 1-17.

32 H. Kim, J. S. Horwitz, G. P. Kushto, Z. H. Kafafi and D. B. Chrisey, Appl. Phys. Lett., 2001, 79, 284.

33 F. Fang, Y. Zhang, X. Wu, Q. Shao and Z. Xie, Mater. Res. Bull., 2015, 68, 240-244.

34 Y. F. Lan, W. C. Peng, Y. H. Lo and J. L. He, Org. Electron., 2010, 11, 670-676.

35 L. Gomez De Arco, Y. Zhang, C. W. Schlenker, K. Ryu, M. E. Thompson and C. Zhou, ACS Nano, 2010, 4, 2865-2873.

36 R. Mientus and K. Ellmer, Surf. Coat. Technol., 1998, 98, 1267-1271.

37 D. S. Bhachu, M. R. Waugh, K. Zeissler, W. R. Branford and I. P. Parkin, Chem. - Eur. J., 2011, 17, 11613-11621.

38 S. Mohri, Y. Hirose, S. Nakao, N. Yamada, T. Shimada and T. Hasegawa, J. Appl. Phys., 2012, 111, 093528.

39 A. Kafizas, N. Noor, P. Carmichael, D. O. Scanlon, C. J. Carmalt and I. P. Parkin, Adv. Funct. Mater., 2014, 24, 1758-1771.

40 L. Cao, L. Zhu, J. Jiang, R. Zhao, Z. Ye and B. Zhao, Sol. Energy Mater. Sol. Cells, 2011, 95, 894-898.

$41 \mathrm{~J} . \mathrm{Hu}$ and R. G. Gordon, Sol. Cells, 1991, 30, 437-450.

42 J. Lee, N. G. Subramaniam, J. Lee, J. Lee and T. Kang, Phys. Status Solidi, 2013, 210, 2638-2643.

43 Y.-J. Choi, K.-M. Kang, H.-S. Lee and H.-H. Park, J. Mater. Chem. C, 2015, 3, 8336-8343.

44 L.-H. Wong and Y.-S. Lai, Thin Solid Films, 2015, 583, 205-211.

45 B. N. Pawar, G. Cai, D. Ham, R. S. Mane, T. Ganesh, A. Ghule, R. Sharma, K. D. Jadhava and S.-H. Han, Sol. Energy Mater. Sol. Cells, 2009, 93, 524-527.

46 T. Shirahata, T. Kawaharamura, S. Fujita and H. Orita, Thin Solid Films, 2015, 597, 30-38.

47 H. Agura, A. Suzuki, T. Matsushita, T. Aoki and M. Okuda, Thin Solid Films, 2003, 445, 263-267.

48 R. S. Ajimsha, A. K. Das, P. Misra, M. P. Joshi, L. M. Kukreja, R. Kumar, T. K. Sharma and S. M. Oak, J. Alloys Compd., 2015, 638, 55-58.

49 V. Assunção, E. Fortunato, A. Marques, A. Gonçalves, I. Ferreira, H. Águas and R. Martins, Thin Solid Films, 2003, 442, 102-106.

50 H. Ohta, M. Orita, M. Hirano, H. Tanji, H. Kawazoe and H. Hosono, Appl. Phys. Lett., 2000, 76, 2740.

51 R. Sharma, K. Sehrawat and R. M. Mehra, Curr. Appl. Phys., 2010, 10, 164-170.

52 T. Minami, T. Yamamoto and T. Miyata, Thin Solid Films, 2000, 366, 63-68.

53 J. P. Upadhyay, S. R. Vishwakarma and H. C. Prasad, Thin Solid Films, 1989, 169, 195-204.

54 C. Sotelo-Vazquez, N. Noor, A. Kafizas, R. Quesada-Cabrera, D. O. Scanlon, A. Taylor, J. R. Durrant and I. P. Parkin, Chem. Mater., 2015, 27, 3234-3242.

55 A. A. Dakhel, Sol. Energy, 2012, 86, 126-131.

56 M. E. White, O. Bierwagen, M. Y. Tsai and J. S. Speck, J. Appl. Phys., 2009, 106, 093704.

57 J. Ma, X. Hao, S. Huang, J. Huang, Y. Yang and H. Ma, Appl. Surf. Sci., 2003, 214, 208-213.
58 J. Kane, J. Electrochem. Soc., 1976, 123, 270.

59 F. X. Xiu, Z. Yang, L. J. Mandalapu, D. T. Zhao, J. L. Liu and W. P. Beyermann, Appl. Phys. Lett., 2005, 87, 152101.

60 H. Liang, Y. Chen, X. Xia, Q. Feng, Y. Liu, R. Shen, Y. Luo and G. Du, Thin Solid Films, 2015, 589, 199-202.

61 K. Sieradzka, J. Domaradzki, E. Prociow, M. Mazur and M. Lapinski, Acta Phys. Pol., A, 2009, 116, S-33-S-35.

62 Y. Furubayashi, T. Hitosugi, Y. Yamamoto, K. Inaba, G. Kinoda, Y. Hirose, T. Shimada and T. Hasegawa, Appl. Phys. Lett., 2005, 86, 252101.

63 T. Hitosugi, A. Ueda, S. Nakao, N. Yamada, Y. Furubayashi, Y. Hirose, T. Shimada and T. Hasegawa, Appl. Phys. Lett., 2007, 90, 212106.

64 T. Hitosugi, Y. Furubayashi, A. Ueda, K. Itabashi, K. Inaba, Y. Hirose, G. Kinoda, Y. Yamamoto, T. Shimada and T. Hasegawa, Jpn. J. Appl. Phys., 2005, 44, L1063-L1065.

65 B.-B. Wu, F.-M. Pan and Y.-E. Yang, Chin. Phys. Lett., 2011, 28, 118102.

66 X. Wang, L. Zhi and K. Müllen, Nano Lett., 2008, 8, 323-327. 67 Z. Wu, Z. Chen, X. Du, J. M. Logan, J. Sippel, M. Nikolou, K. Kamaras, J. R. Reynolds, D. B. Tanner, A. F. Hebard and A. G. Rinzler, Science, 2004, 305, 1273-1276.

68 H. Liu, V. Avrutin, N. Izyumskaya, Ü. Özgür and H. Morkoç, Superlattices Microstruct., 2010, 48, 458-484.

69 European Commission, Report on critical raw materials for the EU, Report of the Ad hoc Working Group on defining critical raw materials, 2014.

70 T. Minami, H. Nanto and S. Takata, Jpn. J. Appl. Phys., 1984, 23, L280-L282.

71 R. Pandey, S. Yuldashev, H. D. Nguyen, H. C. Jeon and T. W. Kang, Curr. Appl. Phys., 2012, 12, S56-S58.

72 J. Hu and R. G. Gordon, J. Appl. Phys., 1992, 71, 880.

73 D. Lide, CRC handbook of chemistry and physics: a readyreference book of chemical and physical data, Taylor \& Francis, Boca Raton, 2008.

74 M. N. Islam, T. B. Ghosh, K. L. Chopra and H. N. Acharya, Thin Solid Films, 1996, 280, 20-25.

75 J. J. Lander, J. Phys. Chem. Solids, 1960, 15, 324-334.

76 T. Minami, MRS Bull., 2000, 25, 38-44.

77 M. Hiramatsu, J. Vac. Sci. Technol., A, 1998, 16, 669.

78 Y. Igasaki and H. Saito, J. Appl. Phys., 1991, 70, 3613.

79 T. Minami, K. Oohashi, S. Takata, T. Mouri and N. Ogawa, Thin Solid Films, 1990, 193-194, 721-729.

80 Y. Geng, L. Guo, S.-S. Xu, Q.-Q. Sun, S.-J. Ding, H.-L. Lu and D. W. Zhang, J. Phys. Chem. C, 2011, 115, 12317-12321.

81 H. Kim, J. Horwitz, S. Qadri and D. Chrisey, Thin Solid Films, 2002, 420-421, 107-111.

82 F. Eskandari, M. Ranjbar, P. Kameli and H. Salamati, J. Alloys Compd., 2015, 649, 35-45.

83 S. Boughaba, G. Sproule, J. McCaffrey, M. Islam and M. Graham, Thin Solid Films, 2000, 358, 104-113.

84 P. Mazzolini, P. Gondoni, V. Russo, D. Chrastina, C. S. Casari and A. L. Bassi, J. Phys. Chem. C, 2015, 119, 6988-6997.

85 R. D. Shannon and C. T. Prewitt, Acta Crystallogr., Sect. B: Struct. Crystallogr. Cryst. Chem., 1969, 25, 925-946. 
86 D. Chen, G. Xu, L. Miao, S. Nakao and P. Jin, Surf. Coat. Technol., 2011, 206, 1020-1023.

87 T. Hitosugi, N. Yamada, S. Nakao, Y. Hirose and T. Hasegawa, Phys. Status Solidi, 2010, 207, 1529-1537.

88 D. S. Bhachu, S. Sathasivam, G. Sankar, D. O. Scanlon, G. Cibin, C. J. Carmalt, I. P. Parkin, G. W. Watson, S. M. Bawaked, A. Y. Obaid, S. Al-Thabaiti and S. N. Basahel, Adv. Funct. Mater., 2014, 24, 5075-5085.

89 T. Hitosugi, H. Kamisaka, K. Yamashita, H. Nogawa, Y. Furubayashi, S. Nakao, N. Yamada, A. Chikamatsu, H. Kumigashira, M. Oshima, Y. Hirose, T. Shimada and T. Hasegawa, Appl. Phys. Express, 2008, 1, 111203.

90 W. Yu, X. Liu, L. Pan, J. Li, J. Liu, J. Zhang, P. Li, C. Chen and Z. Sun, Appl. Surf. Sci., 2014, 319, 107-112.

91 J. Xu, Y. Ao, D. Fu and C. Yuan, Appl. Surf. Sci., 2008, 254, 3033-3038.

92 M. Worsdale, A. Rabis, E. Fabbri, T. J. Schmidt and D. Kramer, ECS Trans., 2015, 69, 1167-1178.

93 E. Shanthi, V. Dutta, A. Banerjee and K. L. Chopra, J. Appl. Phys., 1980, 51, 6243.

94 N. Noor, C. K. T. Chew, D. S. Bhachu, M. R. Waugh, C. J. Carmalt and I. P. Parkin, J. Mater. Chem. C, 2015, 3, 9359-9368.

95 Y. Sawada, C. Kobayashi, S. Seki and H. Funakubo, Thin Solid Films, 2002, 409, 46-50.

96 X.-Y. Gao, S.-Y. Wang, J. Li, Y.-X. Zheng, R.-J. Zhang, P. Zhou, Y.-M. Yang and L.-Y. Chen, Thin Solid Films, 2004, 455-456, 438-442.

97 Q. Wan and T. H. Wang, Chem. Commun., 2005, 3841-3843.

98 S. R. Vishwakarma, J. P. Upadhyay and H. C. Prasad, Thin Solid Films, 1989, 176, 99-110.

99 F. Oba, S. R. Nishitani, S. Isotani, H. Adachi and I. Tanaka, J. Appl. Phys., 2001, 90, 824.

100 H. Peng, J. D. Perkins and S. Lany, Chem. Mater., 2014, 26, 4876-4881.

101 X. Ding, F. Fang and J. Jiang, Surf. Coat. Technol., 2013, 231, 67-70.

102 L. L. Kerr, X. Li, M. Canepa and A. J. Sommer, Thin Solid Films, 2007, 515, 5282-5286.
103 S. S. Pan, S. Wang, Y. X. Zhang, Y. Y. Luo, F. Y. Kong, S. C. Xu, J. M. Xu and G. H. Li, Appl. Phys. A: Mater. Sci. Process., 2012, 109, 267-271.

104 C.-C. Lin, M.-C. Chiang and Y.-W. Chen, Thin Solid Films, 2009, 518, 1241-1244.

105 C. E. Knapp and C. J. Carmalt, Chem. Soc. Rev., 2016, 45, 1036-1064.

106 P. Marchand, I. A. Hassan, I. P. Parkin and C. J. Carmalt, Dalton Trans., 2013, 42, 9406-9422.

107 S. D. Cosham, G. Kociok-Köhn, A. L. Johnson, J. A. Hamilton, M. S. Hill, K. C. Molloy and R. Castaing, Eur. J. Inorg. Chem., 2015, 4362-4372.

108 S. J. Kim, K. Choi, B. Lee, Y. Kim and B. H. Hong, Annu. Rev. Mater. Res., 2015, 45, 63-84.

109 W. Shing Koh, C. How Gan, W. Kee Phua, Y. A. Akimov and P. Bai, IEEE J. Sel. Top. Quantum Electron., 2014, 20, 36-42.

110 M. Kemerink, S. Timpanaro, M. M. de Kok, E. A. Meulenkamp and F. J. Touwslager, J. Phys. Chem. B, 2004, 108, 18820-18825.

111 H. Park, J. A. Rowehl, K. K. Kim, V. Bulovic and J. Kong, Nanotechnology, 2010, 21, 505204.

112 H. Park and J. Kong, Adv. Energy Mater., 2014, 4, DOI: 10.1002/aenm.201301280.

113 G. Gu, V. Bulović, P. E. Burrows, S. R. Forrest and M. E. Thompson, Appl. Phys. Lett., 1996, 68, 2606.

114 X. Zhou, M. Pfeiffer, J. S. Huang, J. Blochwitz-Nimoth, D. S. Qin, A. Werner, J. Drechsel, B. Maennig and K. Leo, Appl. Phys. Lett., 2002, 81, 922.

115 H. S. Seo, US Pat., US8227797 B2, 2012.

116 V. Bhosle, J. T. Prater, F. Yang, D. Burk, S. R. Forrest and J. Narayan, J. Appl. Phys., 2007, 102, 023501.

117 H. Li, L. K. Schirra, J. Shim, H. Cheun, B. Kippelen, O. L. A. Monti and J.-L. Bredas, Chem. Mater., 2012, 24, 3044-3055.

118 M. Morales-Masis, F. Dauzou, Q. Jeangros, A. Dabirian, H. Lifka, R. Gierth, M. Ruske, D. Moet, A. Hessler-Wyser and C. Ballif, Adv. Funct. Mater., 2016, 26, 384-392.

119 L.-S. Hung and J. Madathil, Thin Solid Films, 2002, 410, 101-106.

120 K. Lee and A. Heeger, US Pat., US20060211272 A1, 2006. 121 V. Shrotriya and G. Li, US Pat., US20090229667 A1, 2009. 